\title{
The Netrin Receptor DCC Is Required in the Pubertal Organization of Mesocortical Dopamine Circuitry
}

\author{
Colleen Manitt, ${ }^{1}$ Andrea Mimee, ${ }^{1}$ Conrad Eng, ${ }^{1}$ Matthew Pokinko, ${ }^{1}$ Thomas Stroh, ${ }^{2}$ Helen M. Cooper, ${ }^{3}$ Bryan Kolb, ${ }^{4}$ \\ and Cecilia Flores ${ }^{1}$ \\ ${ }^{1}$ Department of Psychiatry, Douglas Mental Health University Institute, McGill University, Montreal, Quebec, Canada, H4H 1R3, ${ }^{2}$ Department of Neurology \\ and Neurosurgery, Montreal Neurological Institute, McGill University, Montreal, Quebec, Canada, H3A 2B4, ${ }^{3}$ Queensland Brain Institute, The University of \\ Queensland, Brisbane, Queensland 4072, Australia, and ${ }^{4}$ Canadian Centre for Behavioural Neuroscience, University of Lethbridge, Lethbridge, Alberta, \\ Canada, T1K 3M4
}

Netrins are guidance cues involved in neural connectivity. We have shown that the netrin-1 receptor DCC (deleted in colorectal cancer) is involved in the functional organization of the mesocorticolimbic dopamine (DA) system. Adult mice with a heterozygous loss-of-function mutation in $d c c$ exhibit changes in indexes of DA function, including DA-related behaviors. These phenotypes are only observed after puberty, a critical period in the maturation of the mesocortical DA projection. Here, we examined whether $d c c$ heterozygous mice exhibit structural changes in medial prefrontal cortex (mPFC) DA synaptic connectivity, before and after puberty. Stereological counts of tyrosine-hydroxylase (TH)-positive varicosities were increased in the cingulate 1 and prelimbic regions of the pregenual mPFC. $d c c$ heterozygous mice also exhibited alterations in the size, complexity, and dendritic spine density of mPFC layer V pyramidal neuron basilar dendritic arbors. Remarkably, these presynaptic and postsynaptic partner phenotypes were not observed in juvenile mice, suggesting that DCC selectively influences the extensive branching and synaptic differentiation that occurs in the maturing mPFC DA circuit at puberty. Immunolabeling experiments in wild-type mice demonstrated that DCC is segregated to TH-positive fibers innervating the nucleus accumbens, with only scarce DCC labeling in mPFC TH-positive fibers. Netrin had an inverted target expression pattern. Thus, DCC-mediated netrin-1 signaling may influence the formation/maintenance of mesocorticolimbic DA topography. In support of this, we report that $d c c$ heterozygous mice exhibit a twofold increase in the density of mPFC DCC/TH-positive varicosities. Our results implicate DCC-mediated netrin-1 signaling in the establishment of mPFC DA circuitry during puberty.

\section{Introduction}

Genetic and adverse environmental events occurring during neural development affect the formation of mesocorticolimbic dopamine (DA) networks, leading to individual differences in susceptibility to DA-related psychopathology (Knable and Weinberger, 1997; Meyer and Feldon, 2009). The cellular and molecular processes mediating these effects are essentially unknown. Our past work identified a role for the netrin-1 receptor DCC (deleted in colorectal cancer) in the functional organization of mesocorticolimbic DA systems (Flores et al., 2005, 2009; Grant et al., 2007, 2009; Yetnikoff et al., 2007, 2010), leading us to propose that DCC-mediated netrin-1 signaling is a mechanism whereby risk factors exert their enduring effects on DA function (Flores,

\footnotetext{
Received Feb. 3, 2011; revised April 12, 2011; accepted April 15, 2011.

Author contributions: C.M. and C.F. designed research; C.M., A.M., C.E., M.P., and B.K. performed research; T.S., H.M.C., and B.K. contributed unpublished reagents/analytic tools; C.M., A.M., C.E., M.P., and C.F. analyzed data; C.M. and C.F. wrote the paper.

This work was funded by the Canadian Institute for Health Research, the Natural Science and Engineering Research Council of Canada, and the Fonds de la Recherche en Santé du Québec. We thank Jane Stewart for critical reading of this manuscript and Susan Ackerman (The Jackson Laboratory) for the original dcc heterozygous breeders.

Correspondence should be addressed to Dr. Cecilia Flores, Department of Psychiatry, Douglas Mental Health University Institute, McGill University, 6875 LaSalle Boulevard, Montreal, Quebec, Canada, H4H 1R3. E-mail: cecilia.flores@mcgill.ca.

DOI:10.1523/JNEUROSCI.0606-11.2011

Copyright $\odot 2011$ the authors $\quad 0270-6474 / 11 / 318381-14 \$ 15.00 / 0$
}

2011). Here, we report that DCC contributes to the organization of mesocorticolimbic DA systems by influencing medial prefrontal cortex (mPFC) DA synaptic connectivity.

Mice that develop with a heterozygous loss-of-function mutation in DCC exhibit profound changes in mesocorticolimbic DA function in adulthood (Flores et al., 2005; Grant et al., 2007; Yetnikoff et al., 2010). dcc heterozygous mice display exaggerated DA release in the $\mathrm{MPFC}$ at baseline and after amphetamine exposure. Conversely, these mice show normal baseline levels of DA concentrations in the nucleus accumbens (NAcc) but decreased amphetamine-induced release relative to wild-type animals. Notably, DA activity in the mPFC can lead to diminished NAcc DA release and behavioral responsiveness to stimulant drugs (Vezina et al., 1991; Doherty and Gratton, 1996; Ventura et al., 2004). Consistent with this, $d c c$ heterozygotes do not exhibit amphetamineinduced deficits in sensorimotor gating and show blunted sensitivity to the locomotor and rewarding effects of this drug. These mice also do not develop amphetamine-induced sensitization. In addition, mPFC tyrosine hydroxylase (TH) expression is increased in $d c c$ heterozygous mice, whereas no differences are observed between genotypes in the NAcc or dorsal striatum. Together, these findings suggest that reduced DCC has a selective effect on mPFC DA circuit development.

Whereas DA striatal projections mature soon after birth, the DA innervation to the mPFC continues to develop until early 
adulthood (Kalsbeek et al., 1988a; Voorn et al., 1988; Rosenberg and Lewis, 1995). The symptoms of psychiatric disorders associated with mesocorticolimbic DA dysfunction, such as schizophrenia, emerge in late adolescence or early adulthood. Similarly, $d c c$ heterozygous mice exhibit the above mentioned phenotypes only after puberty (Grant et al., 2009; Yetnikoff et al., 2010). DCC receptor function may therefore influence the organization of mPFC DA circuitry, and alterations in normal DCC signaling may be involved in orchestrating enduring structural and functional changes in this circuit at puberty.

To assess the role of DCC in the organization of mPFC DA circuitry, we examined structural changes in mesocortical DA inputs and their neuronal targets in $d c c$ heterozygous mice. These studies were conducted in juvenile and adult mice to determine whether a structural phenotype would also emerge only after puberty. Immunolabeling experiments led to the hypothesis that DCC-netrin-1 signaling influences the topographical organization of mesocorticolimbic DA circuitry. Thus, we tested whether $d c c$ haploinsufficiency results in altered $\mathrm{mPFC}$ DCC/TH-positive varicosity innervation specifically. Our results support a temporally and spatially selective role of DCC-mediated netrin- 1 signaling in the establishment of mPFC DA circuitry.

\section{Materials and Methods}

\section{Animals}

All experiments were performed in accordance with the guidelines of the Canadian Council of Animal Care, and all animal procedures were approved by the McGill University/Douglas Hospital Animal Care Committee. All animals were kept on a $12 \mathrm{~h}$ light/dark cycle with ad libitum access to food and water.

Mice. BL/6 adult [postnatal day 60 (P60)] and juvenile male mice (P21) were obtained from Charles River Canada for the immunocytochemical characterization studies. Adult $d c c$ heterozygous $(+/-)$ male mice, originally obtained from Dr. S. Ackerman (The Jackson Laboratory), were maintained on a BL/6 background and bred with female C57BL/6J (BL/6) mice obtained from The Jackson Laboratory. Male heterozygous $(+/-)$ and wild-type $(+/+)$ offspring were used at juvenile $(\mathrm{P} 21 \pm 1)$ and at adult $(\mathrm{P} 75 \pm 15)$ ages for the neuroanatomical analyses. Targeted inactivation of the $d c c$ gene was performed by disrupting exon 3, which encodes most of the second Ig-like domain of the protein, by insertion of a neomycin resistance cassette using homologous recombination (Fazeli et al., 1997). Southern and Western blot analyses were used to confirm proper targeting and complete loss of DCC protein, respectively (Fazeli et al., 1997).

Genotyping. The targeted and wild-type $d c c$ alleles were amplified using an annealing temperature of $54^{\circ} \mathrm{C}$ for 30 cycles with the following oligonucleotides: DCC code, GGT CAT TGA GGT TCC TTT; DCC reverse, AAG ACG ACC ACA CGC GAC; and DCC Neo, TCC TCG TGC TTT ACG GTA TC.

\section{Stereological counts of TH-positive terminals in mesocorticolimbic targets}

Tissue processing. Male mice were anesthetized with an overdose of sodium pentobarbital injected intraperitoneally $(>75 \mathrm{mg} / \mathrm{kg})$. Intracardial perfusion was performed with $50 \mathrm{ml}$ of $0.9 \%$ saline, followed by $75 \mathrm{ml}$ of chilled fixative solution [4\% paraformaldehyde (PFA) and 15\% picric acid in PBS]. Brains were postfixed in fixative for $45 \mathrm{~min}$, followed by an overnight incubation in $30 \%$ sucrose at $4^{\circ} \mathrm{C}$.

Brains were frozen the following day in chilled 2-methylbutane (Fisher Scientific) and sectioned using a Leica SM2000-R sliding microtome. Slicing thickness was set to $25 \mu \mathrm{m}$, and serial free-floating coronal sections were collected in PBS. Every second section was processed for immunohistochemistry (1:2 series). Sections were incubated for $30 \mathrm{~min}$ at room temperature in a solution of $0.3 \%$ hydrogen peroxide and $0.3 \%$ heat-inactivated goat serum in PBS. Tissue sections were blocked for $2 \mathrm{~h}$ at room temperature in $2 \%$ bovine serum albumin, $2 \%$ goat serum, and $0.3 \%$ Triton X-100 in PBS and then incubated in rabbit polyclonal
anti-TH antibody diluted in blocking solution (1:500 dilution; catalog \#AB152; Millipore Bioscience Research Reagents) for $48 \mathrm{~h}$ at $4^{\circ} \mathrm{C}$. Sections were then rinsed in PBS and incubated in goat anti-rabbit biotinylated secondary antibody (1:250 dilution; Vector Laboratories) for $2 \mathrm{~h}$ at room temperature. Sections were incubated in Vectastain Elite $\mathrm{ABC}$ reagent (Vector Laboratories) for $2 \mathrm{~h}$ at room temperature and rinsed. Tissue slices were placed in nickel intensified diaminobenzidine (DAB) to visualize staining (DAB kit; Vector Laboratories). Sections were mounted onto gelatin-coated slides, dehydrated, cleared with xylene, and coverslipped using Permount (Thermo Fisher Scientific).

For the stereological counts of TH-positive varicosities double labeled with DCC, the tissue was processed for immunofluorescence. Brains were fixed by intracardial perfusion with $0.9 \%$ saline, followed by $4 \%$ PFA in $0.1 \mathrm{~m}$ phosphate buffer, $\mathrm{pH}$ 7.5. Tissue sections $(35 \mu \mathrm{m})$ were cut using a vibratome (Leica). The immunohistochemical protocol is described in detail below (see Immunohistochemistry)

Stereological counts of TH-positive varicosities. The density of THpositive varicosities in the inner layers of the cingulate $1(\mathrm{Cg} 1)$, prelimbic (PrL), and infralimbic (IL) regions of the pregenual mPFC was evaluated using a stereological fractionator sampling design (West et al., 1991), with the optical fractionator probe of the Stereoinvestigator software (MicroBrightField). Innervation of the mPFC inner layers was sampled because this region receives the densest terminal projections from VTA DA neurons (Berger et al., 1974; Descarries et al., 1987; Fallon and Loughlin, 1987; Hoover and Vertes, 2007; Van De Werd et al., 2010). Regions of interest were delineated according to the mouse brain atlas (Paxinos and Franklin, 2001), and contours of the TH-positive projection within these regions were traced at $5 \times$ magnification with a Leica DM4000B microscope (Fig. 1A). Stereoinvestigator calculates, for each brain region, a volume (in cubic micrometers) measurement from the contour area, section thickness, and section periodicity (MicroBrightField). Sections spanning Plates 14-18 of the Paxinos and Franklin mouse atlas (Paxinos and Franklin, 2001) were studied. The experiment was restricted to the pregenual $\mathrm{mPFC}$, as in all our previous studies (Flores et al., 2005, 2009; Grant et al., 2007, 2009; Yetnikoff et al., 2007, 2010). Stereoinvestigator calculates the total number of TH-positive varicosities based on the experimenter's random sampling of a known fraction of the region. Counting frame and grid size were chosen to consistently sample $\sim 30$ sites per region. An unbiased counting frame of known area $(25 \times 25 \mu \mathrm{m})$ was superimposed on the tissue, and counts were made at regular predetermined intervals $(x=60 \mu \mathrm{m}, y=60 \mu \mathrm{m})$ from a random start point determined by Stereoinvestigator. Counting was performed at $100 \times$ magnification on 6 of the 12 sections contained within the rostrocaudal borders of our region of interest (1:2 series), delimited according to Plates $14-18$ of the Paxinos and Franklin mouse atlas (Paxinos and Franklin, 2001). Twelve sections were contained within the region of interest in both genotypes. A guard zone was implemented to avoid any inconsistencies present on the cut surface of the section. On average, $21 \%$ of the total volume of each region of interest was sampled. The coefficient of error (CE) was below 0.05 in all animals studied, indicating that our sampling was consistent. Manual counts were performed by an experimenter blind to the experimental groups. For the statistical analysis, the means were based on animal units for the region volume and TH-positive varicosity density (projected total number of TH-positive varicosities per region/projected total volume of region). However, the counts were only obtained from the right hemisphere because of the lateralization of DA systems between hemispheres (Slopsema et al., 1982; Brake et al., 2000; Lupinsky et al., 2010). A two-way ANOVA with genotype and mPFC subregion as betweensubjects variables was conducted to analyze data. An ANOVA test for simple effects was used as a post hoc test to determine differences between groups. The sample sizes were the following: adult $+/+, n=9$; adult $d c c^{+/-}, n=7$; juvenile, $n=7$ per group.

The density of TH-positive varicosities in the NAcc and dorsal striatum was likewise assessed using the optical fractionator probe of the Stereoinvestigator software (MicroBrightField). Sections spanning Plates $14-18$ of the Paxinos and Franklin mouse atlas (Paxinos and Franklin, 2001) were studied. An unbiased counting frame of known area $(8 \times 8 \mu \mathrm{m})$ was superimposed on the tissue contour, and counts were 

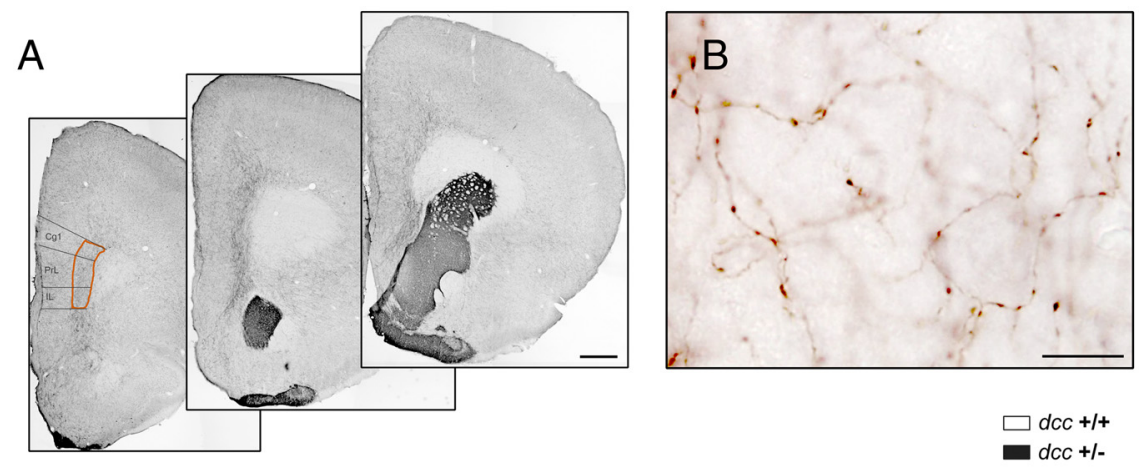

\section{ADULT MPFC}
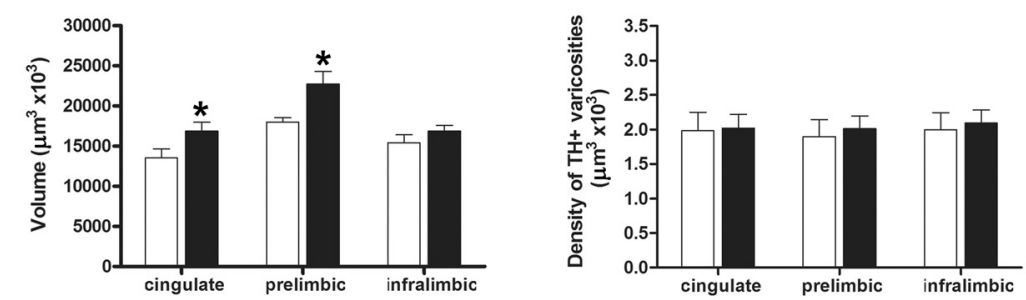

\section{D}

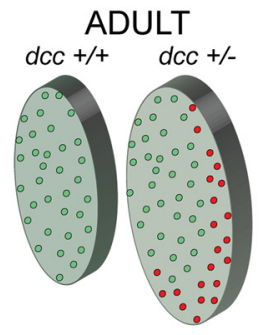

E juvenile mPFC
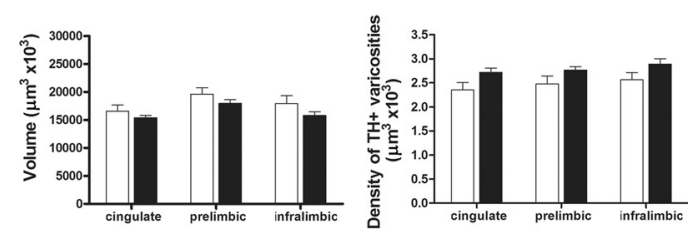

Figure 1. $d \mathrm{dc}^{+/-}$mice exhibit increases in MPFC TH-positive varicosities only after puberty. $\boldsymbol{A}$, Coronal sections of adult mouse forebrain labeled with TH immunoreactivity (DAB) (Paxinos and Franklin, 2001, Plates 14-16). For stereological counting, contours were drawn around the TH-positive fiber innervation to the MPFC inner layers within each subregion of interest (Cg1, PrL, and IL; see red tracing). Scale bar, $500 \mu \mathrm{m}$. B, Micrograph of TH-positive immunoreactivity (DAB) in the mPFC inner layers taken with a $100 \times$ objective. THpositive varicosities were defined as dilated elements associated with axonal processes. Scalebar, $10 \mu \mathrm{m}$. C, The volume of TH-positive fiber innervation (mean \pm SEM) to the $\mathrm{MPFC}$ inner layers was increased in $\mathrm{dcc}^{+/-}$mice $(n=7)$ relative to wild type $(+/+; n=9)$ animals [two-way ANOVA, main effect of genotype: $F_{(1,28)}=5.06, p=0.04$; significant genotype by region interaction: $F_{(2,28)}=3.72, p=0.037$; a post hoc ANOVA test for simple effects indicated a significant effect of genotype in the $C g 1\left(F_{(1,42)}=4.42, p=0.0478\right)$ and $\operatorname{PrL}\left(F_{(1,42)}=\right.$ $9.11, p=0.0065$ ) regions]. No difference was observed in the density of TH-positive varicosities between genotypes. $D, S$ Shematic representation of how adult $d \mathrm{cc}^{+/-}$mice have an increased number of TH-positive varicosities in the DA mesocortical circuit. Although the density of TH-positive varicosities is equal between genotypes [see comparable distribution of all the colored dots (red and green together) between $d c^{+/-}$and $+/+$mice], the span of TH-positive fiber innervation to this region is increased in adult $d c^{+/-}$mice (see increased volume of innervation in $d_{c c^{+/}}$schematic, with additional number of TH-positive varicosities indicated in red). $\boldsymbol{E}$, No differences were observed before puberty in the volume of TH-positive fiber innervation to the mPFC inner layers or in the density of TH-positive varicosities (mean $\pm \mathrm{SEM} ; n=7$ per group).

made at regular predetermined intervals $(x=150 \mu \mathrm{m}, y=200 \mu \mathrm{m})$ from a random start point. Counting was performed at $100 \times$ magnification on four sections per animal in a 1:3 series. The CE was below 0.1 in all animals studied, indicating that our sampling was consistent. The sample sizes were the following: $+/+, n=6 ; d c c^{+/-}, n=7$. Differences between genotypes were assessed by a Student's $t$ test for independent samples for the volume and TH-positive varicosity density in the NAcc and dorsal striatum.

The same method was used to perform stereological counts of THpositive varicosities double labeled with DCC by immunofluorescence. However, image stacks of double-labeled sections (height, $8 \mu \mathrm{m}$; focal step size, $300 \mathrm{~nm}$ ) were scanned before analysis with a Leica DMLB microscope equipped with a motorized Ludl XYZ motorized stage and fluorescent filter shutter using Stereoinvestigator (MicroBrightField). An unbiased counting frame of known area $(100 \times 100 \mu \mathrm{m})$ was superimposed on the image stacks, and counts were made at regular predetermined intervals $(x=200 \mu \mathrm{m}, y=150 \mu \mathrm{m})$ from a random start point, by an experimenter blind to the experimental groups. Analysis was per- formed on five sections per animal in a 1:2 series. The sample size was $n=4$ per group.

Additional technical note. Both the TH and DCC immunolabeling protocols are very robust and yield stable results across experiments. We confirmed this by performing DCC and TH immunolabelings multiple times to assess the reproducibility of the signals. Before our studies, we confirmed that the following parameters were robust and reproducible between sections and across brains using our protocol: (1) overall distribution of immunolabeling throughout the brain, (2) the presence of clearly labeled and distinct varicosities at $100 \times$, and (3) uniform labeling along the $z$-axis. The groups of wild-type and heterozygous animals used in a single experiment were always perfused and immunostained together.

\section{Structural changes in layer $V$ mPFC} pyramidal neurons

Golgi-Cox staining. Juvenile and adult $d c c^{+/-}$ and $+/+$ male mice were given an overdose of sodium pentobarbital ( $>75 \mathrm{mg} / \mathrm{kg}$, i.p.) and were perfused transcardially with $0.9 \%$ saline. The brains were immersed in $20 \mathrm{ml}$ of GolgiCox fixative solution and stored (in the dark) for $14 \mathrm{~d}$ before being transferred to a solution of $30 \%$ sucrose for $7 \mathrm{~d}$. The tissue was cut into 200 - $\mu$ m-thick sections using a Vibratome (Leica) and developed using a method described by Gibb and Kolb (1998).

Anatomical analysis. Basilar dendritic arbors and spine density of layer V mPFC pyramidal neurons were analyzed. In a previous study, we identified reduced spine density in basilar dendrites of layer V, but not layer III, pyramidal neurons of $d c c^{+/-}$mice (Grant et al., 2007). Thus, our current analysis was restricted to layer $\mathrm{V}$ pyramidal neurons. Neurons from the Cg1, PrL, and IL subregions of the pregenual mPFC were analyzed.

A Leica model DM4000 microscope equipped with a Ludl XYZ motorized stage was used to identify cells, trace dendritic arbors, and quantify dendritic spines. Relevant regions were first identified at low magnification $(5 \times$ objective). Only dendritic trees of a cell that was intact, well impregnated, and not obscured by blood vessels, astrocytes, or heavy clusters of dendrites from other cells were included in the analyses. Five cells from each hemisphere were analyzed. Neurolucida software (MicroBrightField) was used to (1) trace the dendritic arbors of selected cells, (2) perform Sholl analysis on dendritic arbors, and (3) quantify dendritic arbor length, dendrite number ( $20 \times$ objective), and the spine density on selected dendrite segments $(100 \times$ objective). For both dendritic arbor and spine density analysis, the same neurons were sampled. One dendritic segment (third-order tip or greater) was analyzed per neuron. Spines were always counted from the last branch point to the terminal tip of the dendrite. No attempt was made to correct for the fact that some spines are obscured from view, so the measure of spine density necessarily underestimates total spine density.

Anatomical analysis was conducted blind to treatment condition. The sample sizes were the following: adult $+/+, n=6$ animals; adult $\mathrm{dcc}^{+/-}$, $n=7$ animals; juvenile, $n=9$ animals per group. A total of 10 cells was analyzed per animal, five cells per hemisphere. Statistical analyses were performed, as described previously (Robinson and Kolb, 1999a; Grant et al., 2007; Flores et al., 2009), by averaging across cells for each hemisphere, i.e., hemisphere was the unit of analysis, after confirmation that 
there were no significant hemispheric differences in the parameters measured. Thus, the statistical $N$ was double that of the number of animals in a given group $(n)$. Two means were generated from each animal for statistical analysis, one mean from five cells in the right hemisphere and one from the five cells analyzed in the left hemisphere. In our experiments, the value of $N$ was 12 for the $+/+$ group and 14 for the $d c c^{+/-}$ group in the adult experiment. For both groups in the juvenile experiment, $N$ was 18 .

Group differences were determined by a Student's $t$ test for independent samples for the spine density, and dendritic arbor length and dendrite number parameters. A two-way ANOVA was performed on the Sholl analysis, followed by a Bonferroni's post hoc test.

\section{Immunohistochemistry}

Antibodies. Polyclonal chicken anti-mouse netrin-1 used at 1:5000 (Novus Biologicals), monoclonal mouse anti-TH used at 1:300 (MAB318; Millipore Bioscience Research Reagents), polyclonal rabbit anti-TH used at 1:500 (AB152; Millipore Bioscience Research Reagents), polyclonal rabbit antimouse DCC used at 1:500 (antibody \#2473, Dr. H. M. Cooper, University of Queensland, Brisbane, QLD, Australia) (Seaman et al., 2001), monoclonal anti-SMI-32 used at 1:1000 (clone SMI-32; Sternberger Monoclonals), and monoclonal mouse anti-parvalbumin used at 1:2000 (clone parv-19; Sigma-Aldrich).

Primary antibody characterization. The rabbit anti-DCC polyclonal antiserum (antibody \#2473) (Seaman et al., 2001) was raised against the C-terminal peptide (SEESHKPTEDPASV) corresponding to amino acids 1406-1419 of the mouse DCC protein (Cooper et al., 1995). The specificity of the antibody has been tested previously by preincubating the antiserum with the peptide antigen before incubating with sections (Seaman et al., 2001; Osborne et al., 2005). Osborne et al. (2005) reported a reduction in DCC immunoreactivity after antibody preadsorption but also noted that decreased labeling was less dramatic in regions of high DCC expression. Thus, we tested the specificity of the anti-DCC antibody further by confirming the absence of DCC immunolabeling in ventral midbrain sections of newborn $d c c$ homozygous mice (see Fig. $4 C$, inset). These results underscore the fact that substantial yet incomplete antibody blocking can still reflect antibody specificity.

The chicken anti-mouse netrin-1 antibody (Novus Biologicals) was tested by Western blot. Lysates from whole rat brain were run alongside rat liver, which does not express netrin-1 (Kennedy et al., 1994). A band of $\sim 75 \mathrm{kDa}$ was detected in adult rat brain, consistent with the predicted molecular weight of rat netrin-1. This band, however, was not detected in liver (data not shown). Furthermore, preadsorption of the netrin-1 antibody with a 10-fold excess of recombinant mouse netrin-1 (R \& D Systems) before immunolabeling abolished netrin immunoreactivity in regions of low netrin expression and dramatically reduced netrin labeling in areas of high expression (see Fig. $3 C$, inset). These results are reminiscent of the reports by Osborne et al. (2005) discussed above in which the DCC antibody blocking experiments did not completely abolish the immunoreactive signal (see above), despite the fact that we demonstrated here that the antibody does not produce a signal in $d c c$ homozygous tissue.

The mouse anti-TH antibody (MAB318; Millipore Bioscience Research Reagents) recognizes specifically an epitope on the regulatory $\mathrm{N}$ terminus of TH (Wolf and Kapatos, 1989). On Western blot, it recognizes a single band of $\sim 60 \mathrm{kDa}$, which corresponds to the predicted molecular weight for TH and does not react with other closely related catecholamine enzymes, including dopamine- $\beta$-hydroxylase (according to the technical information of the manufacturer). The rabbit polyclonal anti-TH antibody (AB152; Millipore Bioscience Research Reagents) was raised against denatured $\mathrm{TH}$ from rat pheochromocytoma. On Western blot, this antibody recognizes a single band of $\sim 60 \mathrm{kDa}$ molecular weight corresponding to the $\mathrm{TH}$ protein (according to the technical information of the manufacturer). This antibody labels midbrain DA neuron cell bodies and terminals in wild-type mice but not in mice that have a nonfunctional TH gene (Hnasko et al., 2006). The mouse anti-SMI-32 antibody (Sternberger Monoclonals) was raised against a nonphosphorylated epitope in neurofilament $\mathrm{H}$ and recognizes two bands on Western blot (200 and 180 $\mathrm{kDa}$; according to the technical information of the manufacturer). This antibody has been shown to recognize subpopulations of pyramidal neurons
(Sternberger and Sternberger, 1983; Hof et al., 1995). The mouse antiparvalbumin antibody (Sigma-Aldrich) was raised against purified frog muscle parvalbumin and also recognizes parvalbumin $(12 \mathrm{kDa})$ from several species, including rat, rabbit, fish, and goat (according to the technical information of the manufacturer).

Juvenile and adult male mice ( $n=6$ per group) were anesthetized with an overdose of sodium pentobarbital ( $>75 \mathrm{mg} / \mathrm{kg}$, i.p.) and were perfused intracardially with $0.9 \%$ saline, followed by a fixative solution $(4 \%$ PFA in $0.1 \mathrm{M}$ phosphate buffer, $\mathrm{pH} 7.5$ ). Brains were sectioned at $35 \mu \mathrm{m}$ on a vibratome (Leica). Free-floating sections were used immediately for immunohistochemical processing.

Mouse brain sections were collected and rinsed in PBS and incubated in blocking solution (M.O.M. kit; Vector Laboratories) for $2 \mathrm{~h}$, followed by second blocking step in $2 \%$ bovine serum albumin, $0.2 \%$ Tween 20 in PBS at room temperature. Sections were incubated $48-72 \mathrm{~h}$ at $4^{\circ} \mathrm{C}$ with combinations of primary antibodies diluted in the second blocking solution. Immunocytochemical experiments with netrin-1 immunoreactivity included an antigen retrieval step that consisted of heating the free-floating sections up to $90^{\circ} \mathrm{C}$ before blocking and primary antibody incubation. Immunostaining was visualized with either Alexa Fluor 488- or Alexa Fluor 555-conjugated secondary antibodies raised in goat (1:500; Invitrogen).

The immunohistochemical analyses were performed in triplicate once the protocols were optimized. This applies to the following double-labeling studies performed in adult and juvenile male mice: netrin $+\mathrm{TH}$; parvalbumin + TH; parvalbumin + netrin; netrin + SMI-32; DCC + TH. Six to 10 mice were used during the optimization of immunocytochemical protocols. Six mice were used in the final studies that were conducted to map immunolabeling patterns (two animals, repeated three times).

\section{Microscopy and image analysis}

Immunofluorescence was visualized using either of the following. (1) A Leica DM4000B microscope was used equipped with a Ludl XYZ motorized stage and filter cubes appropriate for detection of Alexa Fluor 488 and 555. Images were captured using a digital Microfire camera and PictureFrame software (MicroBrightField). (2) A Nikon PCM2000 laser-scanning confocal microscope was used equipped with argon (488 nm excitation; 10\% neutral density filter) and helium/neon (543 nm excitation) lasers. Confocal images of Alexa Fluor 488 and 555 were obtained simultaneously, below saturation levels, with minimal gain and contrast enhancement.

\section{Results}

Postpubertal increase in TH-positive varicosities in the $\mathrm{MPFC}$ of $d c c^{+/-}$mice

Here, we examined whether $d c c^{+/-}$mice exhibit underlying structural differences in mPFC DA connectivity by performing stereological counts of the number of $\mathrm{TH}$-immunoreactive varicosities in the Cg1, PrL, and IL regions of the pregenual mPFC, before and after puberty (Stereoinvestigator fractionator software; MicroBrightField).

$\mathrm{TH}$-positive varicosities were used as the counting unit to obtain a measure of TH-positive presynaptic terminal density. Varicosities represent sites where neurotransmitter synthesis, packaging, release, and reuptake most often occur (Benes et al., 1996). Varicosities were defined as dilated elements associated with axonal processes (Parish et al., 2002) and were thus only counted if they were clearly associated with an axon when visualized with a $100 \times$ objective (Fig. $1 B$ ). The span (i.e., volume measurement in cubic micrometers) of the mPFC TH-positive projection was calculated by Stereoinvestigator from contours drawn around the area containing $\mathrm{TH}$-positive fibers in the inner cortical layers of each cortical subregion of interest (Cg1, PrL, and IL) (Fig. 1A). The tracings were performed on micrographs taken with a $5 \times$ objective to clearly distinguish this heavily innervated area relative to the other cortical layers (Finkelstein et al., 2000; Horne et al., 2008) (Fig. 1A).

As shown in Figure $1 C$, the volume (in cubic micrometers) occupied by $\mathrm{TH}$-positive fiber innervation to the pregenual 
mPFC of adult $d c c^{+/-}$mice was significantly increased compared with wild-type littermates (Fig. 1C, first graph: two-way ANOVA, main effect of genotype, $\left.F_{(1,28)}=5.06, p=0.04\right)$. This effect was dependent on mPFC subregion, with the prelimbic cortex exhibiting the most robust increase in TH-positive fiber volume [Fig. $1 C$, first graph: significant genotype $\times$ region interaction, $F_{(2,28)}$ $=3.72, p=0.037$; a post hoc ANOVA test for simple effects revealed a significant effect of genotype in the $\operatorname{Cg} 1\left(F_{(1,42)}=4.42\right.$, $p=0.0478)$ and $\operatorname{PrL}\left(F_{(1,42)}=9.11, p=0.0065\right)$ regions $]$. We found no difference in the density of $\mathrm{TH}$-positive varicosities between genotypes (Fig. 1C, second graph: two-way ANOVA, main effect of genotype, $F_{(1,28)}=0.07, p=0.79$; genotype $\times$ region interaction, $\left.F_{(2,28)}=0.57, p=0.57\right)$. These data indicate that adult $d c c^{+/-}$mice have an increased number of TH-positive varicosities: whereas the density of varicosities is equal between genotypes, the span (in cubic micrometers) of TH-positive fiber innervation to this region is increased in adult $\mathrm{dcc}^{+/-}$mice (Fig. $1 D)$. Consistent with this, a specific increase in the total number of $\mathrm{TH}$-positive varicosities in the $\mathrm{Cg} 1$ and PrL mPFC was observed in $\mathrm{dcc}^{+/-}$mice (total number of TH-positive varicosities in the Cg1 $\left.+\operatorname{PrL}, t_{(30)}=1.969, p=0.05\right)$ (data not shown).

We measured the density of TH-positive varicosities and the volume (in cubic micrometers) of TH-positive fiber innervation in the NAcc and dorsal striatum of adult $d c^{+/-}$and $+/+$mice. No differences in either measure were observed between genotypes (NAcc volume, $t_{(11)}=1.67, p=0.12$; NAcc density, $t_{(11)}=0.7, p=0.5$; dorsal striatum volume, $t_{(11)}=0.91, p=0.38$; dorsal striatum density, $t_{(11)}=0.08, p=0.9$ ) (data not shown), suggesting that $d c c$ haploinsufficiency induces structural changes in the DA mesocorticolimbic system that are selective for the MPFC DA projection.

We did not find differences between genotypes in the volume (in cubic micrometers), density, or total number of $\mathrm{mPFC}$ TH-positive varicosities in juvenile mice (Fig. 1 E: volume of the TH-positive DA innervation, two-way ANOVA, $F_{(2,24)}=1.60, p=0.23$; density of $\mathrm{TH}$-positive varicosities, two-way ANOVA, $\left.F_{(2,24)}=3.75, p=0.08\right)$. Thus, although $\mathrm{dcc}^{+/-}$mice have an increased number of $\mathrm{TH}$-positive varicosities within the mPFC in adulthood, these differences are not detected before puberty, suggesting that events happening at puberty go awry in these mice.

\section{Postpubertal alterations in dendritic arbor size and complexity of mPFC layer V pyramidal neurons in $\mathrm{dcc}^{+/-}$ mice}

We previously reported that adult $d c c^{+/-}$mice exhibit a significant $\sim 40 \%$ reduction in basilar dendritic spine density in layer $\mathrm{V}$ mPFC neurons compared with adult $+/+$ mice (Grant et al., 2007) (Fig. 2A,C). This reduction was specific to pyramidal neurons localized in this cortical layer, which is a major region of DA innervation to the mPFC (Kalsbeek et al., 1988a). Consistent with this, analysis of the basilar dendritic arbor of layer $\mathrm{V}$ pyramidal neurons in adult $d c c^{+/-}$mice indicated that these neurons have fewer dendrites and a shorter total dendritic arbor length than their wild-type counterparts (Fig. $2 B, D$ : dendrite number, $t_{(24)}=$ 2.88, $p=0.008$; Fig. $2 B, E$ : total dendritic arbor length, $t_{(24)}=$ $2.51, p=0.019)$. Sholl analysis determined that dendritic arbors are less branched closer to the cell body, indicating that $d c c^{+/-}$ mice exhibit morphological alterations in the organization of layer $\mathrm{V}$ pyramidal neuron basilar dendritic arbors compared with $+/+$ mice [Fig. 2B,F: two-way repeated-measures ANOVA, main effect of genotype, $F_{(1,225)}=6.53 p=0.017$; genotype $\times$ Sholl ring (in cubic micrometers) interaction, $F_{(9,225)}=3.58, p=$ 0.0003; Bonferroni's post hoc test, $d c c^{+/-}$vs $+/+$mice at 40,60 , and
$80 \mu \mathrm{m}$ rings, $p<0.05]$. An overall assessment of the distribution of these structural differences between genotypes across the mPFC subregions suggest that pyramidal neurons exhibit these alterations within the three regions examined (Cg1, PrL, and IL).

In contrast, the structural changes in layer $\mathrm{V}$ pyramidal neurons were not observed before puberty. Juvenile $\mathrm{dcc}^{+/-}$and $+/+$ mice did not differ in layer $\mathrm{V}$ pyramidal neuron basilar dendritic spine density (Fig. 2G,I: $t_{(34)}=0.76, p=0.45$ ), dendritic arbor length, or dendrite number (Fig. $2 H, K$ : length, $t_{(34)}=1.42, p=$ 0.17 ; Fig. $2 H$, J: dendrite number, $\left.t_{(34)}=1.64, p=0.11\right)$, nor were there any alterations in dendritic arbor morphology (Fig. $2 \mathrm{H}, \mathrm{L}$ : two-way repeated-measures ANOVA, main effect of genotype, $\left.F_{(1,306)}=2.58, p=0.12\right)$. These results indicate that $d c c$ haploinsufficiency results in structural changes in layer $\mathrm{V}$ pyramidal neuron basilar dendritic arbors only after puberty. The morphological alterations in $d c c^{+/-}$mice observed here may reflect changes that are intrinsic to these neurons or that may be a consequence of the DA hyperfunction observed in these mice (for review, see Seamans and Yang, 2004). Of note, all the dendritic arbor parameters measured were robustly maintained in wildtype mice between the juvenile and adult periods (Fig. 2D, E, F, for wild-type adult compared with Fig. $2 J, K, L$, for wild-type juvenile). This indicates that basilar dendritic arbors of layer $\mathrm{V}$ pyramidal neurons in $d c c^{+/-}$mice undergo a loss of dendrite number, as well as a reduction in arbor length and complexity around puberty.

\section{mPFC TH-positive innervation is sparsely labeled with DCC and overlaps with the most intense region of netrin-1 immunoreactivity}

To gain insight into how DCC-mediated netrin function may contribute to the normal organization of synaptic connectivity in the mPFC DA system, we characterized the distribution of netrin- 1 and netrin- 1 receptor expression in the NAcc and $\mathrm{mPFC}$ of wild-type mice before and after puberty. We found that netrin- 1 is indeed expressed in the MPFC (Fig. 3). Widespread robust immunoreactivity was observed in neuronal cell bodies across all cortical layers (Fig. 3A-D). However, netrin-1 immunoreactivity was clearly more intense in the region overlapping with the dense $\mathrm{TH}$-positive fiber innervation of the inner layers (Fig. 3A-D). Two major cortical target cells of the DA mesocortical projection are pyramidal neurons and parvalbumin-positive GABA interneurons (Van Eden et al., 1987; Smiley and Goldman-Rakic, 1993; Cowan et al., 1994; Sesack et al., 1998). Double-labeling experiments confirmed that netrin- 1 is present in most layer $\mathrm{V}$ pyramidal neurons (Fig. $3 J-L)$ and a subset $(\sim 50 \%)$ of parvalbumin-positive GABA interneurons (Fig. 3E-H).

Examination of netrin-1 immunoreactivity in the mPFC of juvenile mice did not reveal any differences in the pattern of netrin-1 expression compared with adults (data not shown). However, the density, shape, and distribution of TH-positive varicosities in the juvenile animal were considerably reduced and less complex compared with the adult (data not shown).

We next analyzed DCC expression in TH-positive fibers in the adult $\mathrm{mPFC}$ of wild-type mice. A subset of TH-positive fibers was colabeled with DCC in the mPFC, but these double-labeled fibers were extremely sparse (Fig. $4 A, A^{I}-C, C^{I}$ ). The vast majority of TH-positive fibers in the inner layers of the mPFC did not express detectable levels of DCC (Fig. $4 A-F$ ). We also observed thicker DCC-positive fibers that were TH immunonegative (Fig. $4 A, A^{I}-C, C^{I}$ ).

Again, the distribution of DCC immunoreactivity in the mPFC of juvenile mice appeared very similar to the pattern ob- 


\section{ADULT LAYER V}

A

adult $d c c+/+$

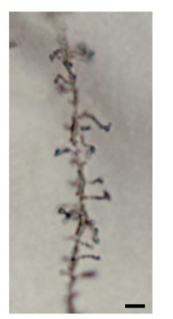

C

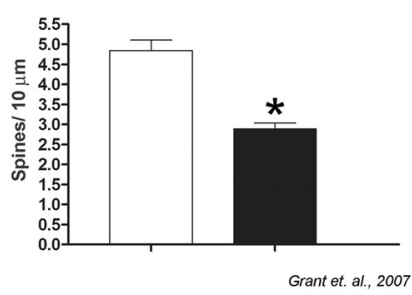

\section{juvenile LAYER V}

G
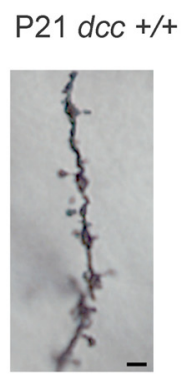

I

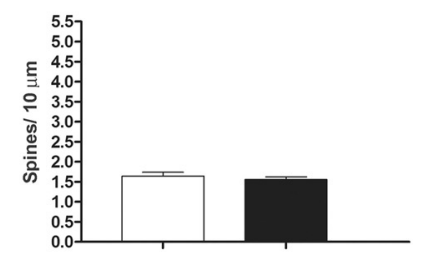

adult $d c c+/+$

adult $d c c+/-$
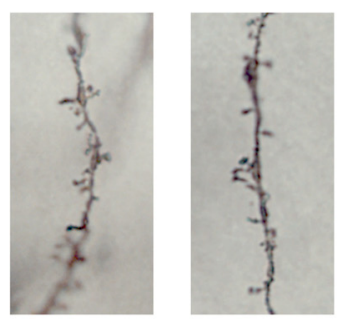

D
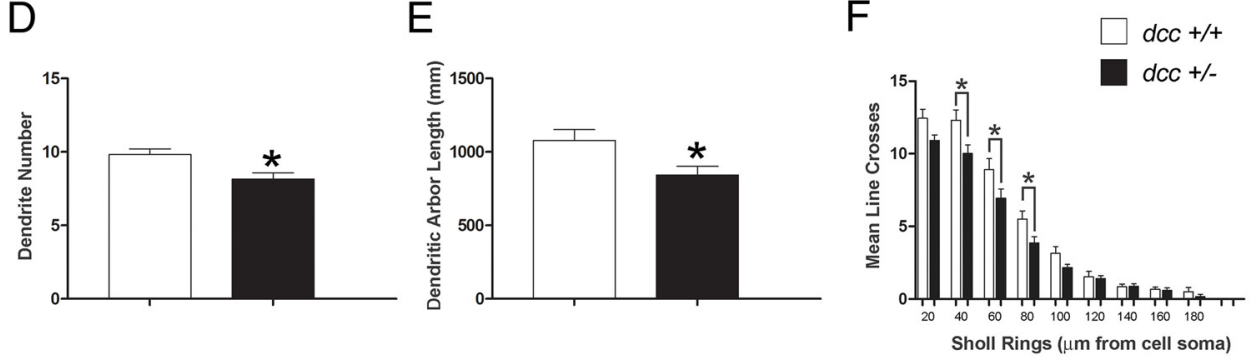

P21 dcc+/-

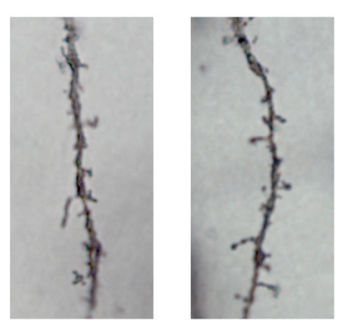

J

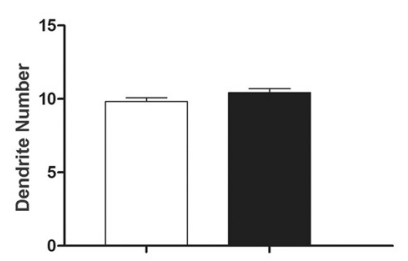

B

E

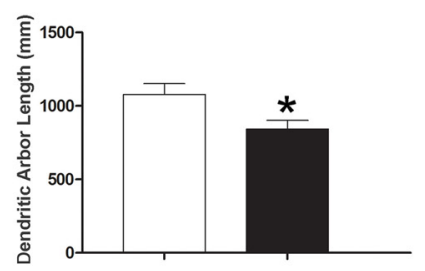

F

$\mathrm{P} 21 d c c+/+$

$\mathrm{H}$

adult $d c c+/-$
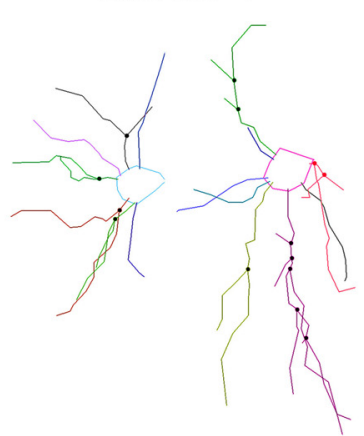

$\square d c c+/+$

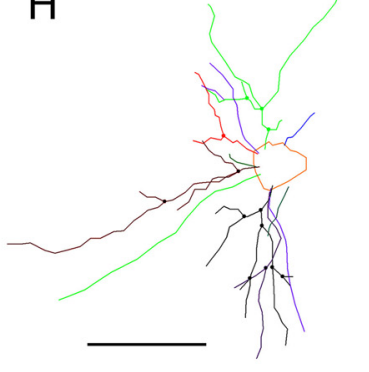

K

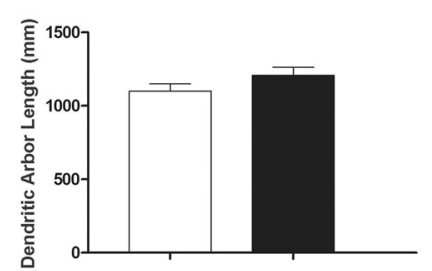

$\mathrm{P} 21 \mathrm{dcc}+/-$
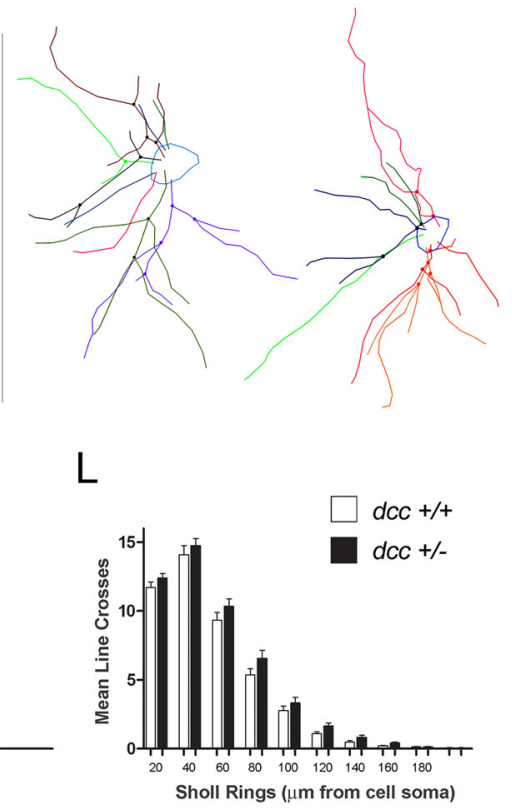

Figure 2. $\quad \mathrm{dcc}^{+/-}$mice exhibit structural alterations in layer V basilar dendritic arbors only after puberty. $\boldsymbol{A}, \mathbf{G}$, Representative micrographs of $G$ olgi-Cox-labeled layer V pyramidal neuron basilar dendritic spines in $\mathrm{dcc}^{+/-}$and $+/+$mice $\left(\boldsymbol{A}\right.$, adult; $\boldsymbol{G}$, juvenile). $\boldsymbol{B}, \boldsymbol{H}$, Representative tracings of adult layer V pyramidal neuron basilar dendritic arbors from $d c \boldsymbol{c}^{+/-}$and $+/+$mice $(\boldsymbol{B}$, adult; $\boldsymbol{H}$, juvenile). Scale bars: $\boldsymbol{A}, \boldsymbol{G}, 5 \mu \mathrm{m} ; \boldsymbol{B}, \boldsymbol{H}, 50 \mu \mathrm{m}$. $\boldsymbol{C}-\boldsymbol{F}, \mathbf{d c c}{ }^{+/-}$mice exhibit a significant $\sim 40 \%$ reduction in basilar dendritic spine density (mean \pm SEM) in layer $V$ mPF neurons compared with adult $+/+$ mice $(\boldsymbol{C})$ (reproduced from Grant et al., 2007). $\boldsymbol{D}, \boldsymbol{E}$, In addition, layer V pyramidal neurons in adult dec ${ }^{+/-}$mice $(n=6)$ have fewer dendrites $(\boldsymbol{D})$ and shorter dendritic arbors $(\boldsymbol{E})$ than $+/+$ $(n=7)$ littermates (dendrite number, $t_{(24)}=2.88, p=0.008$; arbor length, $\left.t_{(24)}=2.51, p=0.019\right)$. Data are shown as mean \pm SEM. $\boldsymbol{F}$, Sholl analysis determined that $d c c^{+/-}$mice exhibit morphological alterations in the organization of layer V pyramidal neuron basilar dendritic arbors compared with $+/+$ mice (two-way repeated measures ANOVA, main effect of genotype: $F_{(1,225)}=6.53, p=0.017$; genotype by Sholl ring $(\mu \mathrm{m})$ interaction, $F_{(9,225)}=3.58 ; p=0.0003$, Bonferroni post hoc test, dcc ${ }^{-1+}$ versus wild-type at 40,60 , and $80 \mu \mathrm{m}$ rings, $\left.p<0.05\right)$. Data are shown as mean \pm SEM. I-L, The structural changes in layer V pyramidal neurons were not observed before puberty. Juvenile $d c c^{+/-}$and $+/+$mice $(n=9$ per group) did not differ in layer $V$ pyramidal neuron basilar dendritic spine density $(\boldsymbol{I})$, dendritic arbor length $(\boldsymbol{J})$, dendrite number $(\boldsymbol{K})$, or dendritic arbor morphology determined by Sholl analysis $(\boldsymbol{L})$. Shown as mean \pm SEM.

served in adulthood; a sparse distribution of DCC-positive fibers was observed within the TH-positive projection to the cortical inner layers (data not shown). Together, our immunolabeling studies indicate that the complementary pattern of netrin-1 and DCC expression in the mPFC is present from the juvenile period into adulthood.
All TH-positive fibers colabel with DCC immunoreactivity in the NAcc and innervate sites of lowest netrin-1 expression As clearly observed in Figure 5, netrin-1 expression in dorsal striatum as well as in forebrain limbic regions, including the NAcc, ventral pallidum, and olfactory tubercle, is considerably less intense than netrin-1 expression in surrounding cortical re- 

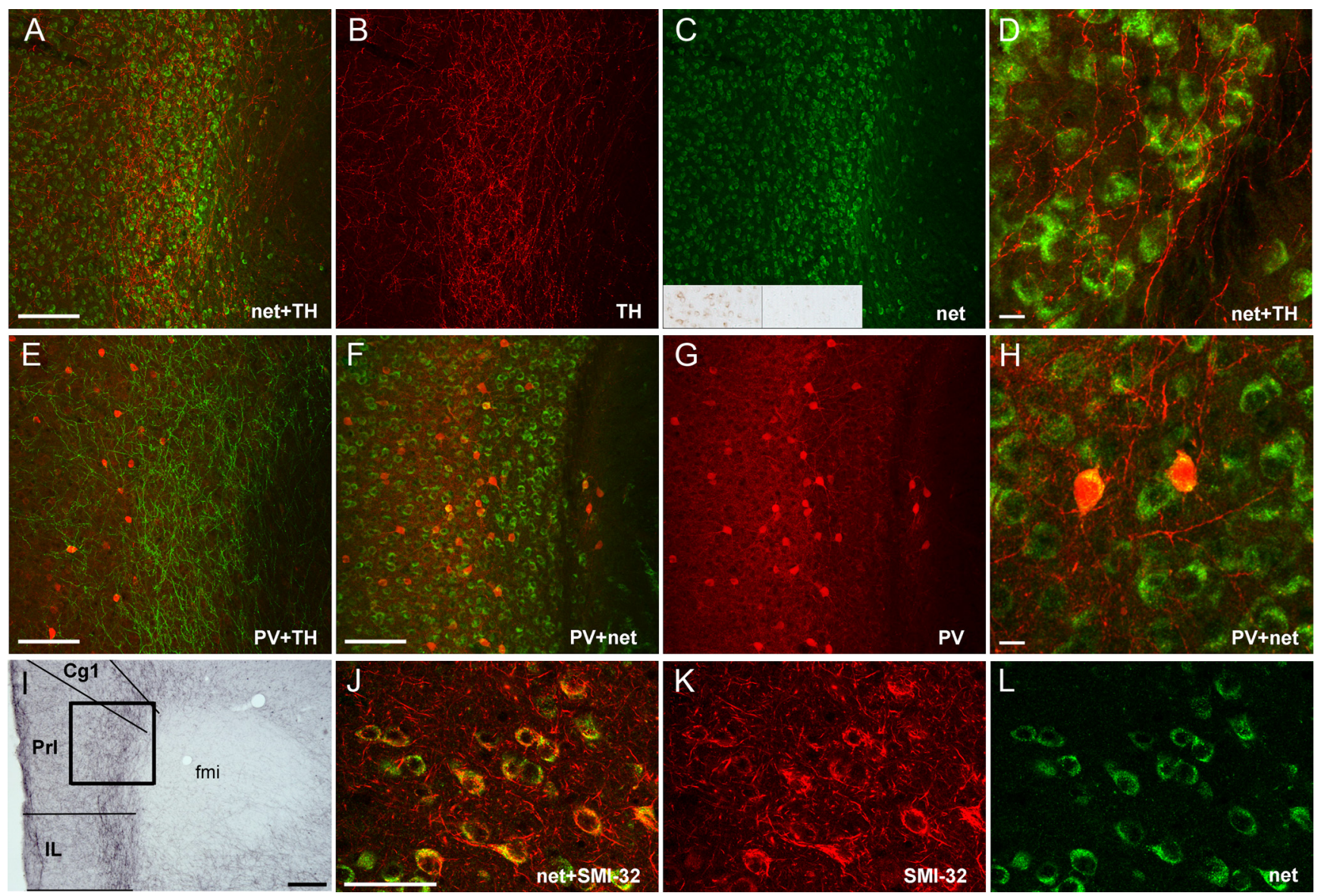

Figure 3. Netrin-1 is ubiquitously expressed in the mPFC. A micrograph in I illustrates TH-immunoreactive fibers (DAB) innervating the $\mathrm{mPFC}$ in a coronal section through the adult mouse forebrain. A bounding box surrounds a region of the $\mathrm{C} g 1$ and PrL cortical inner layers that is presented in the panels with immunofluorescent confocal stacks in the rest of the figure. fmi, Forceps minor of the corpus callosum. Scale bar: $I, 250 \mu \mathrm{m}$. $\boldsymbol{A}-\boldsymbol{C}$, In the adult + I+ mouse, a coronal section through the mPFC double labeled with TH and netrin-1 (net) immunoreactivity shows widespread netrin-1 expression in neuronal cell bodies across cortical layers. The region overlapping with the TH-positive fiber innervation of the cortical inner layers ( $\boldsymbol{B}$, red) was observed to exhibit the most intense netrin-1 immunoreactivity ( $\boldsymbol{C}$, green). Inset, Immunoreactivity was not detected when the netrin-1 antibody was preincubated with recombinant mouse netrin-1 protein (left, netrin immunoreactivity in a coronal section through adult mouse mPFC visualized with DAB; right, netrin immunoreactivity after preincubation with recombinant mouse netrin-1). D, High magnification of netrin-1 and TH double labeling in layers V-VI of the prelimbic mPFC. Scale bars: $\boldsymbol{A}-\boldsymbol{C}, 100 \mu \mathrm{m} ; \boldsymbol{D}, 10 \mu \mathrm{m}$. $\boldsymbol{E}-\boldsymbol{H}, \boldsymbol{E}$ illustrates the distribution of parvalbumin (PV)-positive immunoreactivity (red) relative to the TH-positive (green) fiber innervation in the $\mathrm{mPFC}$ inner layers. Double-labeling experiments confirmed that netrin- $\mathbf{1}(\boldsymbol{F}, \mathrm{green})$ is present in a subset of parvalbumin-positive $(\boldsymbol{F}, \boldsymbol{G}$, red) GABA interneurons. Higher magnification of netrin- 1 and parvalbumin colabeling in layer $V$ of the prelimbic $\mathrm{PPFC}(\boldsymbol{H})$. Scale bars: $\boldsymbol{E}-\boldsymbol{G}, 100 \mu \mathrm{m} ; \boldsymbol{H}, 10 \mu \mathrm{m}$. $\boldsymbol{J}-\boldsymbol{L}$, The majority of SMI-32-positive layer $V$ pyramidal neurons $(\boldsymbol{K}$, red) colabeled with netrin-1 immunoreactivity $(\boldsymbol{L}$, green). The same pattern of netrin-1 immunoreactivity is observed in juvenile mice (data not shown). Scale bar: $\boldsymbol{J}-\boldsymbol{L}, 50$ $\mu \mathrm{m}$. The sample size for these studies was $n=6$ per group. The immunohistochemical analyses were performed in triplicate after optimization of the immunolabeling protocols. Six mice were studied in each of the double-labeling studies to map expression patterns ( 2 animals, repeated 3 times). Antibody specificity experiments for anti-netrin were performed in triplicates. Six wild-type mice were studied (2 wild-type mouse brains, repeated three times).

gions (Fig. 5A-F). Netrin-1-immunoreactive cells were distributed throughout the NAcc core and shell (Fig. $4 A, A^{I}-B, B^{I}, H-$ $M$ ), consistent with a previous report (Shatzmiller et al., 2008). The overall pattern of netrin-1 immunoreactivity in mesocorticolimbic targets suggests that DA fibers projecting to the mPFC innervate a region of high netrin- 1 expression but that DA fibers projecting to the NAcc innervate a region of low netrin-1 expression. The distribution of netrin-1 immunoreactivity in the NAcc and dorsal striatum of juvenile mice appeared very similar to that of adult mice (data not shown).

DCC immunoreactivity in TH-positive fibers innervating forebrain limbic regions and the dorsal striatum had an expression profile that differed dramatically from $\mathrm{TH}$-positive fibers innervating the mPFC. DA fibers innervating the NAcc and dorsal striatum exhibited complete colabeling of TH and DCC immunoreactivity (Fig. 6). DCC labeling was uniform throughout the anterior NAcc core and shell (Fig. 6A-D) (Paxinos and Franklin, 2001, Plates 14-17), with intense DCC immunoreac- tivity detected in fibers and in varicosities (Fig. $6 L-Q$ ). The pattern and intensity of DCC immunoreactivity in more caudal striatal sections indicated that the dorsomedial accumbens becomes more intensely labeled relative to other striatal regions (Fig. 6E,F) (Paxinos and Franklin, 2001, Plates 18-22), consistent with a previous report (Osborne et al., 2005). Thus, THpositive fibers innervating the NAcc and dorsal striatum express high levels of DCC, whereas TH-positive fiber input to the mPFC is sparsely labeled with DCC immunoreactivity, which is often faint. Consistent with this observation, there are TH-positive/DCC-negative fibers with a vertical orientation medial to the NAcc. These fibers are likely to innervate the mPFC (Fig. 6H-K).

The same pattern of DCC expression in TH-positive fibers of the NAcc and dorsal striatum was observed in juvenile and adult mice. TH-positive/DCC-immunonegative fibers with a vertical orientation medial to the NAcc are also clearly present in the juvenile brain (data not shown). 
$d_{c c}^{+/-}$mice exhibit netrin-1 and DCC expression patterns comparable with wild-type littermates

We detected the same pattern of netrin-1 expression in the mPFC, dorsal striatum, and forebrain limbic regions of $d c c^{+/-}$and wild-type mice (data not shown). This was the case for both juvenile and adult mice.

Similar to the pattern observed in wild-type animals, complete colabeling of DCC and TH-positive fibers was detected in the dorsal striatum and forebrain limbic regions of juvenile and adult $d c c^{+/-}$ mice (data not shown). Consistent with previous reports using Western blot analysis (Fazeli et al., 1997; Flores et al., 2005; Grant et al., 2007), the intensity of DCC immunoreactivity was reduced in both juvenile and adult $d c c^{+/-}$mice relative to wild-type littermates. The distribution of $\mathrm{TH}$, netrin, and DCC immunolabeling are similar in wild-type mice bred in our colony and in those purchased from the supplier at Charles River Canada (immunolabeling results described in Figs. 3-6).

\section{Increased density of DCC/TH-positive} varicosities in the mPFC of $d c c^{+/-}$mice Our data show that the NAcc DA projection, which expresses intense widespread DCC labeling, innervates a region of low netrin-1 expression. The converse is true for the $\mathrm{mPFC}$ DA projection; $\mathrm{TH}$-positive fibers, which are sparsely labeled with DCC expression, innervate a region of highest netrin-1 expression. This complementary pattern of netrin-1 (target) versus DCC (fiber input) expression may be influencing the establishment and/or maintenance of the topography of mesocorticolimbic DA circuitry. Thus, TH-positive axons in $\mathrm{dcc}^{+/-}$mice, which express reduced DCC levels, may be more likely to localize to regions of intense netrin- 1 expression, such as the $\mathrm{mPFC}$. If this is true, the increased TH-positive innervation observed in the Cg1 and PrL mPFC of adult $d c c^{+/-}$mice should coincide with a greater density of varicosities that are double labeled with DCC and $\mathrm{TH}$.

To test this idea, we examined differences in the density of $\mathrm{DCC} / \mathrm{TH}$-positive varicosities in the mPFC between adult $\mathrm{dcc} \mathrm{C}^{+/-}$ and $+/+$ mice. We performed stereological counts of $\mathrm{TH}-$ positive varicosities double labeled with DCC using fluorescence microscopy in the $\mathrm{Cg} 1, \mathrm{PrL}$, and IL regions of the pregenual mPFC. Similar to our first stereological study, the mesocortical DA projection was delineated by tracing the $\mathrm{TH}$-positive fiber innervation to the mPFC. The tracings were performed on micrographs taken with a $4 \times$ objective, a magnification at which only the dense innervation to the inner layers can be clearly detected. Two types of DCC varicosities were counted within these regions of DA innervation: (1) DCC-positive varicosities that were $\mathrm{TH}$ positive, and (2) DCC-positive varicosities that were found on TH-negative fibers.

Figure $7 A$ depicts the tracings around the TH-positive innervation to the $\mathrm{mPFC}$ inner layers from the five serial sections taken from one brain, overlaid one on top of the other. A tracing from each brain slice included the three cortical regions of interest (Cg1, blue; PrL, green; IL, purple). The small icons scattered throughout the contours represent the distribution of DCC/THpositive varicosities (pink stars) and DCC-positive varicosities on TH-negative fibers (green triangles).

The density of DCC/TH-positive varicosities was significantly increased in the Cg1 and PrL regions of the pregenual mPFC in $d_{c c}^{+/-}$mice relative to wild-type littermates (Fig. $7 B-E$ : a twoway ANOVA, main effect of genotype, $\left.F_{(1,6)}=19.91, p=0.02\right)$. A compelling differential pattern of innervation between the two populations of DCC-positive varicosities was revealed across $\mathrm{mPFC}$ subregions. DCC/TH-positive varicosities were predominantly located in the $\mathrm{Cg} 1$ and PrL regions, the same two $\mathrm{mPFC}$ subregions in which we detected changes in the span of $\mathrm{TH}$ positive fiber innervation (Fig. 1C). The number of DCC/THpositive varicosities within the IL region was exceedingly scarce. As a result, the Gunderson coefficient of error $(m=1)$ for the $\mathrm{DCC} / \mathrm{TH}$-positive varicosity counts in the IL was above 0.1 . Thus, we were unable to obtain an accurate calculation of the density of $\mathrm{DCC} / \mathrm{TH}$-positive varicosities in the IL from our random sampling of this region.

The opposite result was obtained when we analyzed the density of DCC-positive varicosities in TH-negative fibers (Fig. $7 A, F, G)$. First, these varicosities were predominantly localized within the region of the IL cortex overlapping with TH-positive fiber innervation (Fig. 7A). The presence of these DCC-positive/ 


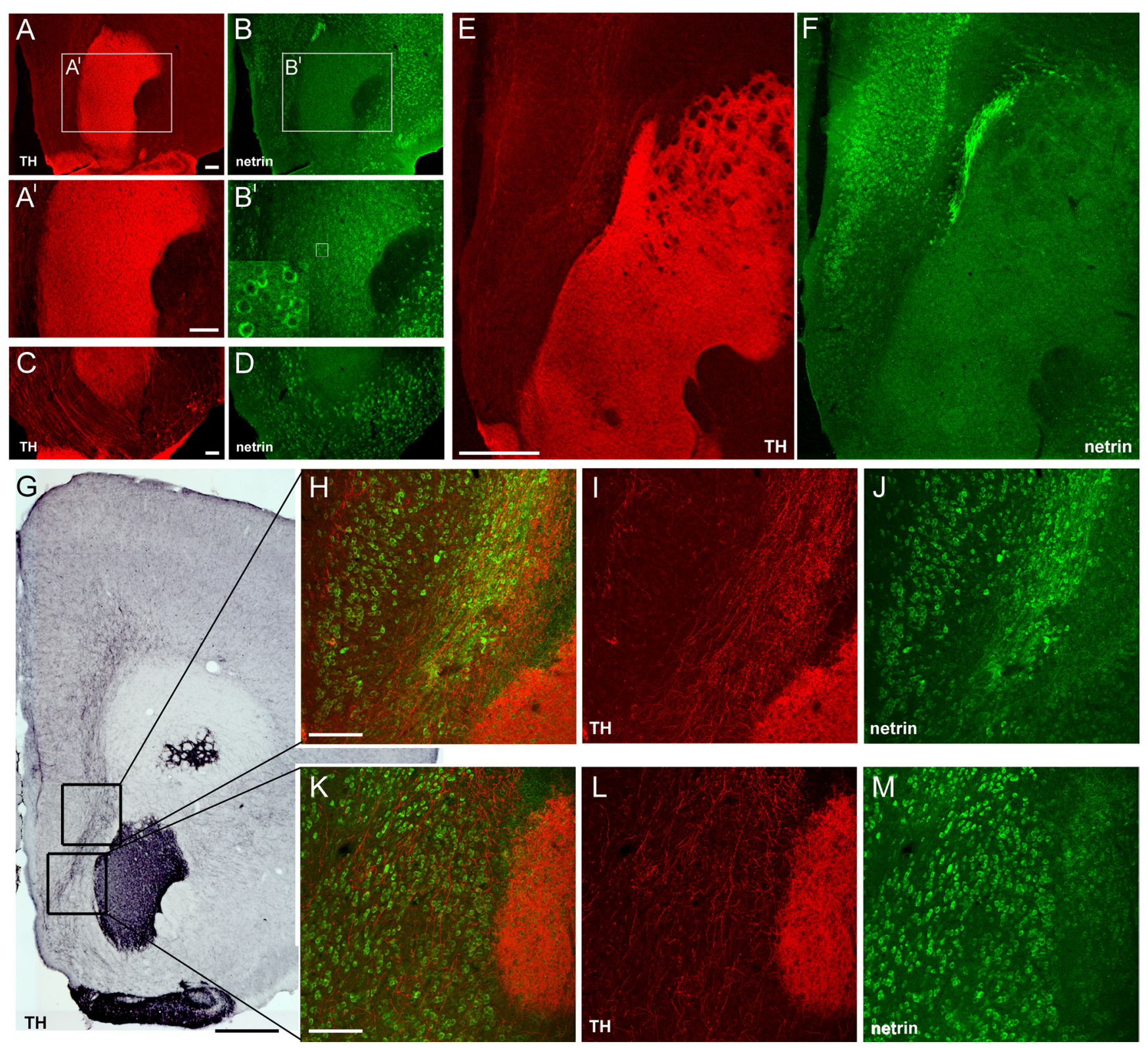

Figure 5. The NAcc and dorsal striatum are regions of low netrin-1 expression. $A-F$, Micrographs of coronal sections through the NAcc and dorsal striatum of wild-type mice double labeled with netrin-1 and TH immunofluorescence (Paxinos and Franklin, 2001, Plates 15-18). $\boldsymbol{A}, \boldsymbol{B}, \mathrm{A}$ low level of netrin-1 immunoreactivity is present in the NAcc relative to surrounding cortical regions. However, the area within the bounding box $\left(\boldsymbol{A}^{\prime}, \boldsymbol{B}^{\prime}\right)$ illustrates the presence of clear but weak labeling in cell bodies of the NAcc. $C, D$, Netrin-1 immunolabeling is also more intense outside TH-positive regions in the ventral forebrain. $\boldsymbol{E}, \boldsymbol{F}$, Netrin-1 labeling is more intense in regions surrounding the NAcc and dorsal striatum in a more caudal section of adult mouse forebrain. $S c a l e$ bars: $A-D$, 100 $\mu \mathrm{m} ; \boldsymbol{E}, \boldsymbol{F}, 500 \mu \mathrm{m} . \boldsymbol{G}$, Micrograph of a coronal section through the wild-type mouse forebrain labeled with TH immunoreactivity (DAB). Areas within bounding boxes represent the regions presented in $\boldsymbol{H}-\boldsymbol{M}$ on the right. Scale bar, $500 \mu \mathrm{m}$. $\boldsymbol{H}-\boldsymbol{M}$, Confocal stacks of netrin-1 and TH double labeling clearly illustrate the dramatic difference in intensity of netrin- 1 immunoreactivity between the region overlapping with fibers projecting to the mPFC and that of the NAcc. Scale bars: $\boldsymbol{H}-\boldsymbol{M}, 100 \mu \mathrm{m}$. The sample size for these studies was $n=6$ per group. Experiments examining netrin and TH immunoreactivity were performed in triplicate after optimization of the immunolabeling protocol. Six mice were studied to map expression patterns ( 2 animals, repeated 3 times).

TH-negative varicosities in the Cg1 and PrL regions was too scarce to obtain accurate sampling results, and comparisons were therefore only made in the IL region. Second, as shown in Figure $7 \mathrm{H}, \mathrm{dcc}^{+/-}$mice exhibited a reduction in the density of DCCpositive/TH-negative varicosities $\left(t_{(6)}=2.632, p=0.04\right)$. The identity of these fibers remains to be determined.

Together, these results suggest that a twofold increase in DCC/ TH-positive varicosities, specifically, may underlie the overall increase in TH-positive innervation to the $\mathrm{mPFC}$ in $d c^{+/-}$mice that we reported in Figure 1. It is important to note that DCC immunolabeling in the $d c c^{+/-}$mice was less intense compared with wild-type animals; the TH-positive varicosities in the $\mathrm{mPFC}$ double labeled with DCC were fainter in $\mathrm{dcc}^{+/-}$mice. As such, our quantification of DCC/TH-positive varicosities is likely an underestimate of the actual numbers.

\section{Discussion}

Here we show that the span (i.e., volume measurement in cubic micrometers) of $\mathrm{TH}$-positive varicosity innervation to the inner layers of the cingulate and prelimbic regions of the MPFC is enlarged in adult $d c c$ heterozygous mice relative to wild-type littermates. Significantly, these alterations are only observed after puberty, a period of extensive neural reorganization within this region. Conversely, we found no changes in TH-positive innervation in the NAcc of these 
mice, suggesting that the effects of $d c c$ haploinsufficiency on DA mesocorticolimbic systems result in selective alterations in synaptic connectivity within the mPFC DA projection.

In addition, we show that a "high-tolow," "receptor-to-ligand" complementary expression pattern is present in the mPFC and NAcc of adult wild-type mice, with the relationship being inverted in one region compared with the other. Importantly, this complementary pattern does not seem to differ between juvenile and adult mice. Netrin-1 labeling in the $\mathrm{mPFC}$ is intense, particularly in the layers that overlap with robust $\mathrm{TH}$ innervation, which is in stark contrast to the faint expression pattern of netrin-1 in NAcc neurons. Conversely, DCC is segregated to $\mathrm{TH}$-positive axons in the NAcc, with only a few sparse TH-positive fibers coexpressing DCC in the mPFC. These findings suggest that cells with high levels of axonal DCC expression may have a peak affinity for cells with low levels of netrin expression and vice versa. DCC-netrin signaling may therefore play an important role in target selection and in the normal formation and/or maintenance of the topographical organization of mesocorticolimbic DA circuitry. We predicted that, in dcc heterozygous mice, the reduced DCC expression in $\mathrm{TH}$-positive fibers would result in the partial redirection of $\mathrm{TH}$-positive fibers from low- to high-netrin-expressing targets because they would be more likely to fail to undergo target recognition events in the NAcc/dorsal striatum. Consistent with this, we report here that the density of THpositive varicosities colabeled with DCC in the $\mathrm{mPFC}$ is increased by twofold in the cingulate and prelimbic regions, the same cortical subregions in which we identified an increase in the span of DA fiber innervation.

We found reduced dendritic spine density and dendritic arbor complexity in the basilar dendrites of layer $\mathrm{V}$ pyramidal neurons in adult $d c c$ heterozygous mice compared with wild-type littermates. Again, these structural changes were not observed in juvenile $d c c$ heterozygous mice. These results suggest that, in $d c c$ heterozygous mice, DA alterations in the mPFC are accompanied by reorganization of $\mathrm{mPFC}$ neuronal circuitry. The basilar dendrites of layer $\mathrm{V}$ $\mathrm{mPFC}$ pyramidal cells indeed receive direct and indirect input from VTA DA neurons (Penit-Soria et al., 1987; Van Eden et al., 1987; Pirot et al., 1992; Smiley and Goldman-Rakic, 1993; Cowan et al., 1994; Sesack et al., 1998). Moreover, layer V pyramidal neurons can modulate DA transmission in the NAcc (for review, see Tzschentke, 2000).

Together, our results suggest that DCC function is required in the normal maturation of mPFC DA synaptic connectivity dur-
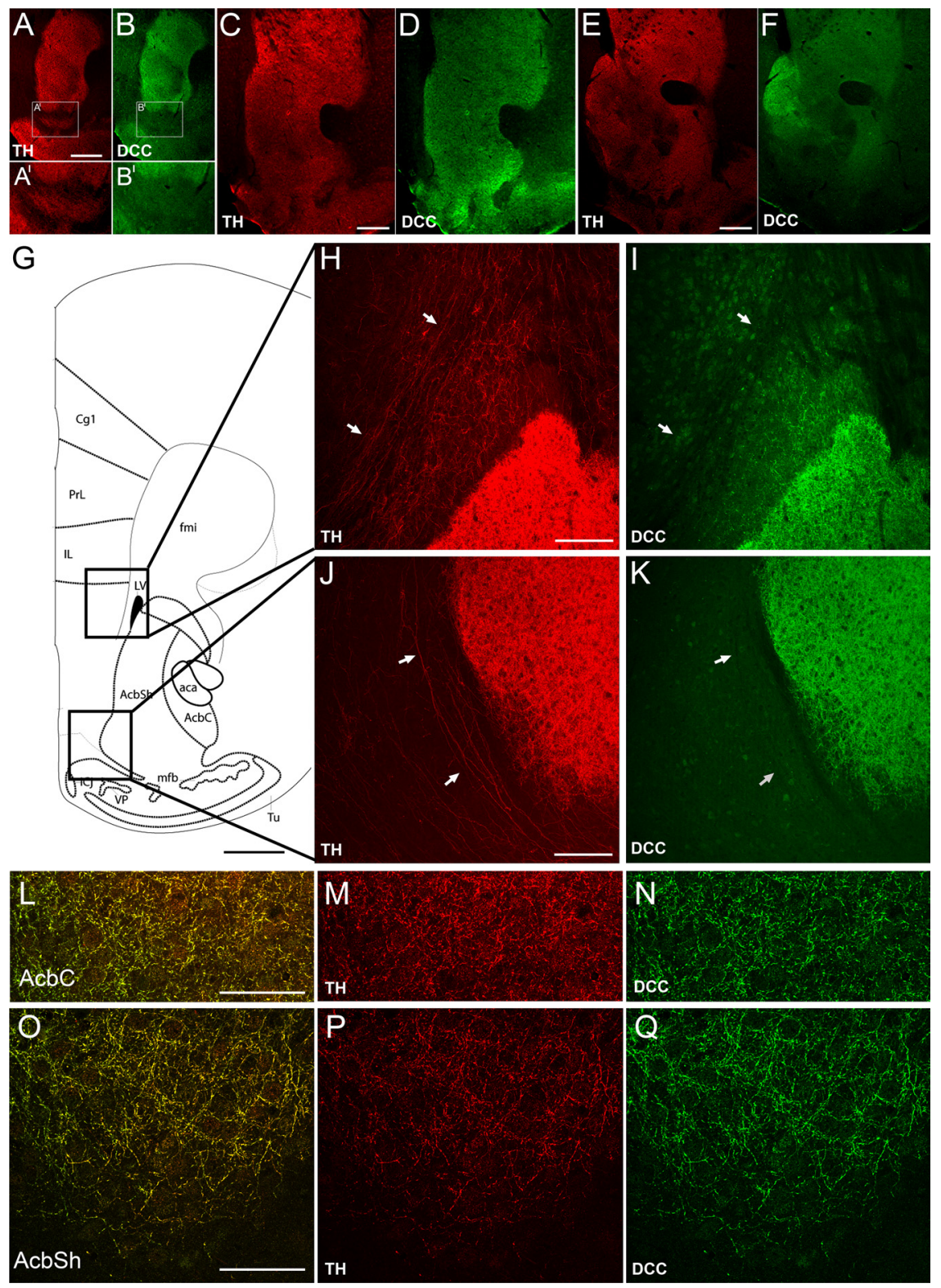

Figure 6. DCC expressing TH-positive fibers segregated to the NAcc projection. $\boldsymbol{A}-\boldsymbol{F}$, Micrographs of DCC and TH double-labeled coronal sections through the NAcc and dorsal striatum in the wild-type mouse forebrain (Paxinos and Franklin, 2001, Plates 14-18). DCC clearly colabels with TH immunoreactivity in these regions $(\boldsymbol{A}, \boldsymbol{B} ; \boldsymbol{C}, \boldsymbol{D} ; \boldsymbol{E}, \boldsymbol{F})$, with the exception of a small population of fibers ventral to the NAcc $\left(\boldsymbol{A}^{\prime}, \boldsymbol{B}^{\prime}\right)$. Scale bars: $\boldsymbol{A}, \boldsymbol{B}, 125 \mu \mathrm{m} ; \boldsymbol{C}-\boldsymbol{F}, 250 \mu \mathrm{m}$. G, Schematic modified from Paxinos and Franklin (2001) with bounding boxes indicating the regions presented in $\boldsymbol{H}, \boldsymbol{I}$ and $\boldsymbol{J}, \boldsymbol{K}$. aca, Anterior part of the anterior commissure; $A c b C$, accumbens nucleus, core; AcbSh, accumbens nucleus, shell; fmi, forceps minor of the corpus callosum; LV, lateral ventricle; MFB, medial forebrain bundle; Tu, olfactory tubercle; VP, ventrolateral thalamic nucleus. $\boldsymbol{H}, \boldsymbol{I}$, The region dorsomedial to the NAcc contains horizontally oriented TH-positive/DCC-negative fibers that are likely innervating the MPFC and other anterodorsal targets. Within this same panel, DCC is clearly colabeled with TH-positive fibers in the NACc. J, $\boldsymbol{K}, \mathrm{DCC}$ and TH immunoreactivity in a region ventromedial to NAcc. Small bundles of vertically oriented TH-positive fibers that do not express DCC are clearly visible medial to the DCC/TH-positive NAcc. Scale bars: $\mathbf{G}, 500 \mu \mathrm{m} ; \boldsymbol{H}-\boldsymbol{K}, 100 \mu \mathrm{m}$. $\boldsymbol{L}-\mathbf{Q}$, Confocal stacks scanned at higher magnification of the NAcc core and shell. Clear colabeling ofDCC and TH are observed in these regions. Scale bars, $50 \mu \mathrm{m}$. The sample size for these studies was $n=6$ per group. Experiments examining DCC and TH immunoreactivity in the NAcc/dorsal striatum were performed in triplicate. Six mice were studied to map the expression patterns ( 2 animals, repeated 3 times).

ing the pubertal period and that alterations in DCC function have enduring functional consequences.

Increased mPFC TH-positive innervation in $d c c$ heterozygous mice: DA or norepinephrine fibers?

Norepinephrine fibers innervate the mPFC (Levitt and Moore, 1979). Thus, the increase in TH-positive varicosity number in 

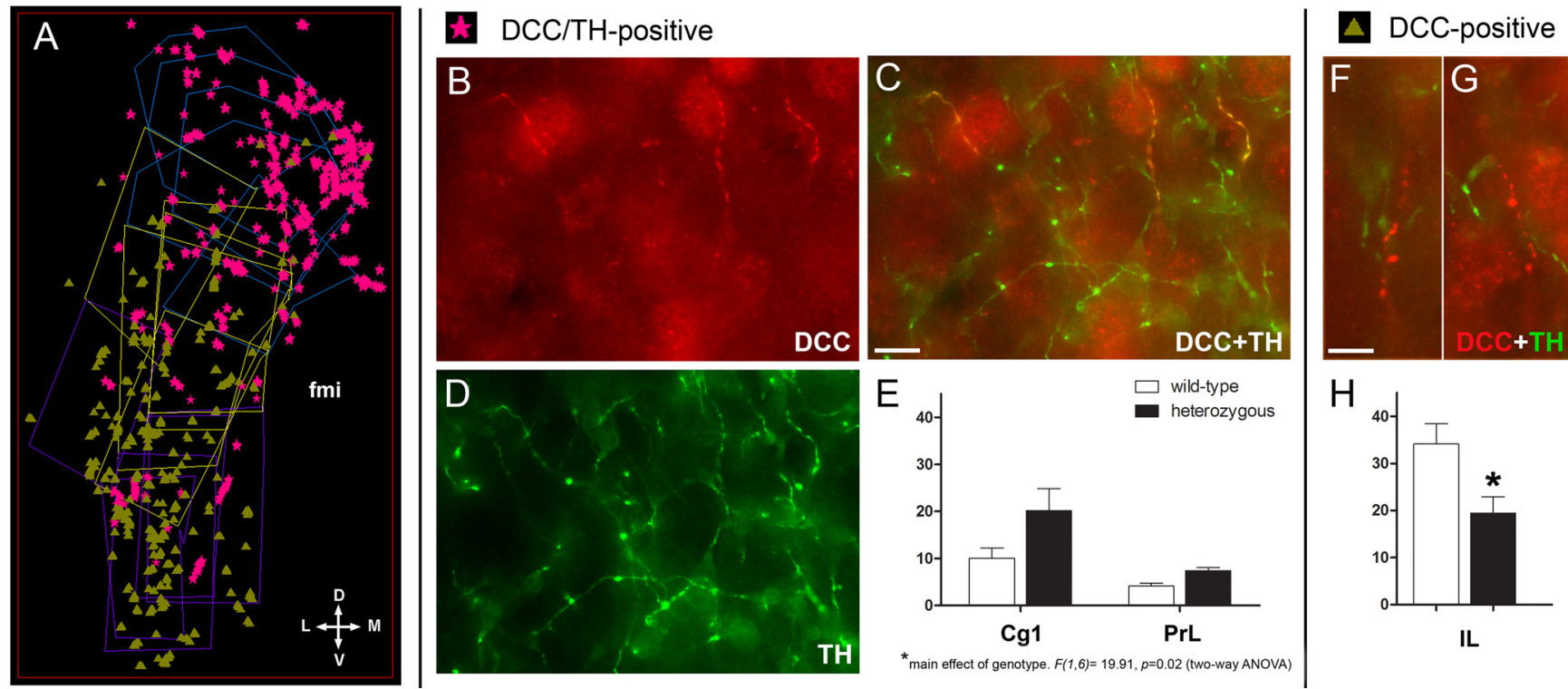

IL

Figure 7. Increased density of mPFC TH/DCC-positive varicosities in adult $d c^{+/-}$mice. $A$, Schematic generated by Neurolucida explorer (MicroBrightField) illustrating the distribution of the DCC/TH-positive (pink stars) and DCC-positive/TH-negative (green triangles) varicosity counts made within the TH-positive projection to the mPFC in one brain. The counts were performed across five coronal slices per brain in the pregenual $\mathrm{mPFC}$. In the schematic, the five contours were overlaid one on top of the other. $D$, Dorsal; $L$, lateral; $M$, medial; $V$, ventral; fmi, forceps minor of the corpus callosum. $\boldsymbol{B}-\boldsymbol{E}$, The density (mean $\pm \mathrm{SEM}$ ) of DCC/TH-positive varicosities is increased in the $\mathrm{Cg} 1$ and PrL $\mathrm{mPFC}$ of $d c c^{+/}$compared with $+/+$mice $(\boldsymbol{E}$, A two-way ANOVA, main effect of genotype: $F_{(1,6)}=19.91, p=0.02, n=4$ per group). A representative micrograph extracted from an image stack used in the stereological counting illustrating $T H(\boldsymbol{B}$, red) and $D C C(\boldsymbol{D}$, green) double labeling in the PrL mPFC (B-D). $\boldsymbol{F}-\boldsymbol{H}$, The density (mean \pm SEM) of DCC-positive/TH-negative varicosities was decreased in the IL mPFC of $d c_{c}{ }^{+/-}$mice compared with wild-type littermates $\left(\boldsymbol{H}, t_{(6)}=2.632\right.$, $p=0.04)$. Two examples of $D C C$ and TH double labeling in the IL $\mathrm{mPFC}(\boldsymbol{F}, \boldsymbol{G})$. The micrographs, which were extracted from an image stack used in the stereological counting, illustrate DCC-positive varicosities that are clearly TH immunonegative and that have a more varicose appearance. Scale bars, $10 \mu \mathrm{m}$.

adult $d c c$ heterozygous mice could be derived from changes in either DA or norepinephrine innervation. Several lines of evidence support the conclusion that the anatomical, neurochemical, and behavioral phenotypes in $d c c$ heterozygous mice are associated with alterations in the DA system, specifically. First, in the present study, mPFC TH-positive axons were thin and showed irregularly spaced varicosities, as previously seen in this region using antibodies for DA (Berger et al., 1983; Van Eden et al., 1987) (Fig. 1B). Norepinephrine-positive fibers have a thick varicose appearance (Levitt and Moore, 1979; Berger et al., 1983). Second, norepinephrine fibers immunostained for the noradrenaline transporter rarely colabel with $\mathrm{TH}$ immunoreactivity (8$10 \%$ ), suggesting that $\mathrm{TH}$ antibodies primarily label DA fibers (Miner et al., 2003). Third, Western blot analysis indicates that $\mathrm{TH}$ immunoreactivity in the mPFC of $d c c$ heterozygous mice is increased, but dopamine $\beta$-hydroxylase is not (Flores et al., 2005). Fourth, microdialysis studies reveal no differences in extracellular mPFC norepinephrine concentrations in dcc heterozygous mice, at baseline or after an amphetamine challenge. In contrast, mPFC DA levels are increased in $d c c$ heterozygous mice (Grant et al., 2007). Finally, our observations that changes in TH-positive innervation are present in adult but not juvenile $d c c$ heterozygous mice coincide with the pubertal maturation of the mPFC DA projection. Norepinephrine innervation to the mPFC matures by the second postnatal week in the rodent (Levitt and Moore, 1979). Nevertheless, we cannot completely rule out the potential involvement of the norepinephrine system in the $d c c$ heterozygous phenotypes because norepinephrine neurons in the locus ceruleus express DCC (Shi et al., 2008).

Possible mechanisms underlying a selective role of DCC in the pubertal maturation of mPFC TH-positive synaptic connectivity The phenotypes observed in adult $d c c$ heterozygous mice suggest that the changes in axonal branching and synaptogenesis that take place in the mPFC during the normal course of pubertal development are different in these mice. This idea is supported by the fact that DCC-mediated netrin-1 signaling has been shown to influence CNS synaptic connectivity (Colón-Ramos et al., 2007; Manitt et al., 2009) and axon branching (Lim et al., 1999; Dent et al., 2004; Tang and Kalil, 2005; Hutchins and Kalil, 2008; Manitt et al., 2009; Xu et al., 2010). A number of factors may explain why dcc haploinsufficiency affects developmental processes that occur precisely during the pubertal period. One is that UNC-5 homolog receptor expression by DA neurons emerges at puberty, whereas DCC is expressed by DA neurons across the lifespan (Manitt et al., 2010). Thus, DCC and UNC-5 homologs are coexpressed by these neurons from puberty into adulthood (Manitt et al., 2010). Significantly, the ratio of DCC to UNC-5 within neurons has been shown to regulate responses to netrin-1 (Hong et al., 1999; Williams et al., 2003; Muramatsu et al., 2010). Thus, the onset of UNC-5 homolog expression by DA neurons at puberty may contribute to the surge in DA axon branching and synaptogenesis that occurs during this period of development (Kalsbeek et al., 1988a; Rosenberg and Lewis, 1995; Benes et al., 2000; Muramatsu et al., 2010), and these processes may therefore be altered in $d c c$ heterozygous mice.

The pubertal changes in the normal organization of mPFC DA circuitry are associated with an increase in the activity of DA neurons projecting to this region (for review, see Spear, 2000). Changes in activity have been shown to modulate axon growth and guidance responses to netrin-1 (Ming et al., 1997, 2001; Shewan et al., 2002; Nishiyama et al., 2003; Moore and Kennedy, 2006; Wu et al., 2006; Moore et al., 2008), in part through influencing the presentation of netrin-1 receptors at the membrane surface (Williams et al., 2003; Bouchard et al., 2004, 2008; Muramatsu et al., 2010). The pubertal increase in mPFC DA activity may naturally affect DCC translocation dynamics in DA fibers during this developmental period, leading to changes in the na- 
ture and magnitude of netrin-1 responses by DA neurons. This could have an important impact on branching and synaptogenesis. These events may be altered in $d c c$ heterozygous mice.

\section{Potential role of DCC function in the topographical organization of DA mesocorticolimbic circuitry}

In our final stereology experiment, we reported a twofold increase in DCC/TH-positive varicosity density in the mPFC of adult $d c c$ heterozygous mice (Fig. 7). This may account for the overall increase in TH-positive innervation to the mPFC observed in these mice (Fig. 1). We have proposed that DCC/THpositive fibers that normally project to low netrin-1-expressing DA targets, including the NAcc, may be ectopically innervating the $\mathrm{mPFC}$ in $d c c$ heterozygous mice. This suggests that an early axon patterning phenotype may already exists in juvenile mice. Increased DCC/TH-positive fiber innervation to the $\mathrm{mPFC}$ may indeed occur when DCC/TH-positive fibers are normally undergoing target recognition events in the NAcc. However, because mPFC TH fibers are primarily undifferentiated before puberty (Kalsbeek et al., 1988b), we may have been unable to detect this with the parameters we examined here and in our previous studies (Grant et al., 2009). That is, a subtle increase in the number of DA fibers projecting to the mPFC may only become detectable with measures of $\mathrm{TH}$-positive varicosities after maturation of the mPFC circuit, once axon terminals have fully differentiated.

Another possible mechanism underlying the increase in $\mathrm{mPFC}$ DCC/TH varicosities observed in adult $d c c$ heterozygous mice is that $d c c$ haploinsufficiency may simply induce a selective increase in branching and synaptogenesis specifically in the small subset of DCC/TH-positive fibers that normally innervate the mPFC. Our future studies will aim to assess whether compromised DCC signaling in TH/DCC-positive fibers indeed affects axonal patterning events between NAcc and mPFC targets.

\section{Altered mPFC DA microcircuitry in $d c c$ heterozygous mice: implications for mesocorticolimbic DA function and the development of psychopathology}

Adult, but not juvenile, $d c c$ heterozygous mice exhibited reduced basal dendritic arbor length, complexity, and spine density. The pubertal emergence of a phenotype in layer $\mathrm{V}$ pyramidal basilar dendritic arbors is likely to be secondary to the emergence of the DA phenotype in this region. Consistent with this, altered DA transmission in the $\mathrm{mPFC}$ has been reported to produce structural changes in mPFC pyramidal neurons (Kalsbeek et al., 1989; Robinson and Kolb, 1999a,b; Robinson et al., 2001; Wang and Deutch, 2008; Wang et al., 2009). It is important to note that decreased basal dendritic length of layer $V$ pyramidal neurons has been described after selective lesion of the DA innervation to the mPFC, both neonatally and in adulthood (Kalsbeek et al., 1989; Wang and Deutch, 2008). The discrepancy between these reports and our findings may indicate that the structural changes in layer $\mathrm{V}$ pyramidal neurons after manipulations in DA function are likely determined by the resulting alterations in DA circuitry rather than the changes in DA concentration per se. Thus, the direction and magnitude of the structural modifications observed in layer $\mathrm{V}$ mPFC pyramidal neurons are most likely dependent on the neuronal subsets that are affected, directly and indirectly, by the changes in DA innervation and function within this region (for review, see Seamans and Yang, 2004). These changes in circuitry may be different across manipulations (i.e., ablation, transgenic mutation).

Layer $\mathrm{V}$ pyramidal neurons are described as receiving both direct and indirect input from VTA DA neurons. The indirect input is from the other major target cells of the mPFC DA projection: parvalbumin-containing GABA interneurons, which provide the predominant local inhibitory input to pyramidal cells (Penit-Soria et al., 1987; Van Eden et al., 1987; Pirot et al., 1992; Smiley and Goldman-Rakic, 1993; Cowan et al., 1994; Sesack et al., 1998). A disruption in the balance between direct inputs to pyramidal neurons and inputs to GABA neurons, resulting from an increased span of TH-positive innervation to the $\mathrm{MPFC}$, may also alter the glutamatergic output of layer $\mathrm{V}$ pyramidal neurons (Peters et al., 2004; Lodge et al., 2009) (for review, see Seamans and Yang, 2004). Notably, several psychiatric disorders, including schizophrenia, depression, and drug abuse (Tan et al., 2007; Davey et al., 2008; Feil et al., 2010), have been associated with altered organization and function of local mPFC circuitry.

It remains to be determined whether the increase in the volume of TH-positive innervation to the $\mathrm{mPFC}$ is associated with a correspondingly "enlarged" cortex or with a cortical region that is unchanged in overall size. However, comparing overall cortical size between wild-type and $d c c$ heterozygous mice would not provide insight regarding the nature of the reorganization of the local mPFC circuitry (i.e., specific cortical layers could change in different directions or in cell density without changing overall cortical size). Nonetheless, future studies will include volumetric analysis to complement current electrophysiological experiments aimed at determining the nature of the functional changes that are associated with the structural alterations observed in pyramidal neurons of adult $d c c$ heterozygous mice.

The structural alterations in $d c c$ heterozygous mice reported here suggest that $d c c$ haploinsufficiency leads to selective changes in the DA innervation to the MPFC as well as associated alterations in the architecture of local mPFC microcircuitry during puberty. Aberrations in the development of the mPFC DA projection have been associated with susceptibility to developing psychopathologies, the symptoms of which tend to be first exhibited in early adulthood. Our findings implicate DCC-mediated netrin signaling in the maturation of mPFC DA neural circuits during puberty and provide a potential mechanism by which alterations in DCC function can produce structural and behavioral abnormalities associated with these disorders. Of particular relevance, $D C C$ heterozygous human subjects have been identified recently, and we are currently assessing whether these individuals exhibit phenotypes in indexes of DA mesocorticolimbic function that are comparable with the ones detected in $d c c$ heterozygous mice (Srour et al., 2010).

\section{References}

Benes FM, Vincent SL, Molloy R, Khan Y (1996) Increased interaction of dopamine-immunoreactive varicosities with GABA neurons of rat medial prefrontal cortex occurs during the postweanling period. Synapse 23:237-245

Benes FM, Taylor JB, Cunningham MC (2000) Convergence and plasticity of monoaminergic systems in the medial prefrontal cortex during the postnatal period: implications for the development of psychopathology. Cereb Cortex 10:1014-1027.

Berger B, Tassin JP, Blanc G, Moyne MA, Thierry AM (1974) Histochemical confirmation for dopaminergic innervation of the rat cerebral cortex after destruction of the noradrenergic ascending pathways. Brain Res 81:332-337

Berger B, Verney C, Gay M, Vigny A (1983) Immunocytochemical characterization of the dopaminergic and noradrenergic innervation of the rat neocortex during early ontogeny. Prog Brain Res 58:263-267.

Bouchard JF, Moore SW, Tritsch NX, Roux PP, Shekarabi M, Barker PA, Kennedy TE (2004) Protein kinase A activation promotes plasma membrane insertion of DCC from an intracellular pool: a novel mechanism regulating commissural axon extension. J Neurosci 24:3040-3050.

Bouchard JF, Horn KE, Stroh T, Kennedy TE (2008) Depolarization recruits 
DCC to the plasma membrane of embryonic cortical neurons and enhances axon extension in response to netrin-1. J Neurochem 107: $398-417$.

Brake WG, Sullivan RM, Gratton A (2000) Perinatal distress leads to lateralized medial prefrontal cortical dopamine hypofunction in adult rats. J Neurosci 20:5538-5543.

Colón-Ramos DA, Margeta MA, Shen K (2007) Glia promote local synaptogenesis through UNC-6 (netrin) signaling in C. elegans. Science 318:103-106.

Cooper HM, Armes P, Britto J, Gad J, Wilks AF (1995) Cloning of the mouse homologue of the deleted in colorectal cancer gene (mDCC) and its expression in the developing mouse embryo. Oncogene 11:2243-2254.

Cowan RL, Sesack SR, Van Bockstaele EJ, Branchereau P, Chain J, Pickel VM (1994) Analysis of synaptic inputs and targets of physiologically characterized neurons in rat frontal cortex: combined in vivo intracellular recording and immunolabeling. Synapse 17:101-114.

Davey CG, Yücel M, Allen NB (2008) The emergence of depression in adolescence: development of the prefrontal cortex and the representation of reward. Neurosci Biobehav Rev 32:1-19.

Dent EW, Barnes AM, Tang F, Kalil K (2004) Netrin-1 and semaphorin 3A promote or inhibit cortical axon branching, respectively, by reorganization of the cytoskeleton. J Neurosci 24:3002-3012.

Descarries L, Lemay B, Doucet G, Berger B (1987) Regional and laminar density of the dopamine innervation in adult rat cerebral cortex. Neuroscience 21:807-824.

Doherty MD, Gratton A (1996) Medial prefrontal cortical D1 receptor modulation of the meso-accumbens dopamine response to stress: an electrochemical study in freely-behaving rats. Brain Res 715:86-97.

Fallon J, Loughlin S (1987) Monoamine innervation of cerebral cortex and a theory of the role of monoamines in cerebral cortex and basal ganglia. In: Cerebral cortex (Jones E, Peters A, eds), pp 41-127. New York: Plenum.

Fazeli A, Dickinson SL, Hermiston ML, Tighe RV, Steen RG, Small CG, Stoeckli ET, Keino-Masu K, Masu M, Rayburn H, Simons J, Bronson RT, Gordon JI, Tessier-Lavigne M, Weinberg RA (1997) Phenotype of mice lacking functional Deleted in colorectal cancer (Dcc) gene. Nature 386:796-804

Feil J, Sheppard D, Fitzgerald PB, Yücel M, Lubman DI, Bradshaw JL (2010) Addiction, compulsive drug seeking, and the role of frontostriatal mechanisms in regulating inhibitory control. Neurosci Biobehav Rev 35:248-275.

Finkelstein DI, Stanic D, Parish CL, Tomas D, Dickson K, Horne MK (2000) Axonal sprouting following lesions of the rat substantia nigra. Neuroscience 97:99-112.

Flores C (2011) Role of netrin-1 in the organization and function of the mesocorticolimbic dopamine system. J Psychiatry Neurosci 36:100171.

Flores C, Manitt C, Rodaros D, Thompson KM, Rajabi H, Luk KC, Tritsch NX, Sadikot AF, Stewart J, Kennedy TE (2005) Netrin receptor deficient mice exhibit functional reorganization of dopaminergic systems and do not sensitize to amphetamine. Mol Psychiatry 10:606-612.

Flores C, Bhardwaj SK, Labelle-Dumais C, Srivastava LK (2009) Altered netrin-1 receptor expression in dopamine terminal regions following neonatal ventral hippocampal lesions in the rat. Synapse 63:54-60.

Gibb R, Kolb B (1998) A method for vibratome sectioning of Golgi-Cox stained whole rat brain. J Neurosci Methods 79:1-4.

Grant A, Hoops D, Labelle-Dumais C, Prévost M, Rajabi H, Kolb B, Stewart J, Arvanitogiannis A, Flores C (2007) Netrin-1 receptor-deficient mice show enhanced mesocortical dopamine transmission and blunted behavioural responses to amphetamine. Eur J Neurosci 26:3215-3228.

Grant A, Speed Z, Labelle-Dumais C, Flores C (2009) Post-pubertal emergence of a dopamine phenotype in netrin-1 receptor-deficient mice. Eur J Neurosci 30:1318-1328.

Hnasko TS, Perez FA, Scouras AD, Stoll EA, Gale SD, Luquet S, Phillips PE, Kremer EJ, Palmiter RD (2006) Cre recombinase-mediated restoration of nigrostriatal dopamine in dopamine-deficient mice reverses hypophagia and bradykinesia. Proc Natl Acad Sci U S A 103:8858-8863.

Hof PR, Nimchinsky EA, Morrison JH (1995) Neurochemical phenotype of corticocortical connections in the macaque monkey: quantitative analysis of a subset of neurofilament protein-immunoreactive projection neurons in frontal, parietal, temporal, and cingulate cortices. J Comp Neurol 362:109-133.

Hong K, Hinck L, Nishiyama M, Poo MM, Tessier-Lavigne M, Stein E (1999) A ligand-gated association between cytoplasmic domains of UNC5 and
DCC family receptors converts netrin-induced growth cone attraction to repulsion. Cell 97:927-941.

Hoover WB, Vertes RP (2007) Anatomical analysis of afferent projections to the medial prefrontal cortex in the rat. Brain Struct Funct 212:149-179.

Horne MK, Lee J, Chen F, Lanning K, Tomas D, Lawrence AJ (2008) Longterm administration of cocaine or serotonin reuptake inhibitors results in anatomical and neurochemical changes in noradrenergic, dopaminergic, and serotonin pathways. J Neurochem 106:1731-1744.

Hutchins BI, Kalil K (2008) Differential outgrowth of axons and their branches is regulated by localized calcium transients. J Neurosci 28:143-153.

Kalsbeek A, Voorn P, Buijs RM, Pool CW, Uylings HB (1988a) Development of the dopaminergic innervation in the prefrontal cortex of the rat. J Comp Neurol 269:58-72.

Kalsbeek A, De Bruin JP, Feenstra MG, Matthijssen MA, Uylings HB (1988b) Neonatal thermal lesions of the mesolimbocortical dopaminergic projection decrease food-hoarding behavior. Brain Res 475:80-90.

Kalsbeek A, Matthijssen MA, Uylings HB (1989) Morphometric analysis of prefrontal cortical development following neonatal lesioning of the dopaminergic mesocortical projection. Exp Brain Res 78:279-289.

Kennedy TE, Serafini T, de la Torre JR, Tessier-Lavigne M (1994) Netrins are diffusible chemotropic factors for commissural axons in the embryonic spinal cord. Cell 78:425-435.

Knable MB, Weinberger DR (1997) Dopamine, the prefrontal cortex and schizophrenia. J Psychopharmacol 11:123-131.

Levitt P, Moore RY (1979) Development of the noradrenergic innervation of neocortex. Brain Res 162:243-259.

Lim YS, Mallapur S, Kao G, Ren XC, Wadsworth WG (1999) Netrin UNC-6 and the regulation of branching and extension of motoneuron axons from the ventral nerve cord of Caenorhabditis elegans. J Neurosci 19:7048-7056.

Lodge DJ, Behrens MM, Grace AA (2009) A loss of parvalbumin-containing interneurons is associated with diminished oscillatory activity in an animal model of schizophrenia. J Neurosci 29:2344-2354.

Lupinsky D, Moquin L, Gratton A (2010) Interhemispheric regulation of the medial prefrontal cortical glutamate stress response in rats. J Neurosci 30:7624-7633.

Manitt C, Nikolakopoulou AM, Almario DR, Nguyen SA, Cohen-Cory S (2009) Netrin participates in the development of retinotectal synaptic connectivity by modulating axon arborization and synapse formation in the developing brain. J Neurosci 29:11065-11077.

Manitt C, Labelle-Dumais C, Eng C, Grant A, Mimee A, Stroh T, Flores C (2010) Peri-pubertal emergence of UNC-5 homologue expression by dopamine neurons in rodents. PLoS One 5:e11463.

Meyer U, Feldon J (2009) Prenatal exposure to infection: a primary mechanism for abnormal dopaminergic development in schizophrenia. Psychopharmacology (Berl) 206:587-602.

Miner LH, Schroeter S, Blakely RD, Sesack SR (2003) Ultrastructural localization of the norepinephrine transporter in superficial and deep layers of the rat prelimbic prefrontal cortex and its spatial relationship to probable dopamine terminals. J Comp Neurol 466:478-494.

Ming GL, Song HJ, Berninger B, Holt CE, Tessier-Lavigne M, Poo MM (1997) cAMP-dependent growth cone guidance by netrin-1. Neuron 19:1225-1235.

Ming G, Henley J, Tessier-Lavigne M, Song H, Poo M (2001) Electrical activity modulates growth cone guidance by diffusible factors. Neuron 29:441-452.

Moore SW, Kennedy TE (2006) Protein kinase A regulates the sensitivity of spinal commissural axon turning to netrin-1 but does not switch between chemoattraction and chemorepulsion. J Neurosci 26:2419-2423.

Moore SW, Lai Wing Sun K, Xie F, Barker PA, Conti M, Kennedy TE (2008) Soluble adenylyl cyclase is not required for axon guidance to netrin-1. J Neurosci 28:3920-3924.

Muramatsu R, Nakahara S, Ichikawa J, Watanabe K, Matsuki N, Koyama R (2010) The ratio of "deleted in colorectal cancer" to "uncoordinated-5A" netrin-1 receptors on the growth cone regulates mossy fibre directionality. Brain 133:60-75.

Nishiyama M, Hoshino A, Tsai L, Henley JR, Goshima Y, Tessier-Lavigne M, Poo MM, Hong K (2003) Cyclic AMP/GMP-dependent modulation of $\mathrm{Ca} 2+$ channels sets the polarity of nerve growth-cone turning. Nature 423:990-995.

Osborne PB, Halliday GM, Cooper HM, Keast JR (2005) Localization of 
immunoreactivity for deleted in colorectal cancer (DCC), the receptor for the guidance factor netrin-1, in ventral tier dopamine projection pathways in adult rodents. Neuroscience 131:671-681.

Parish CL, Stanic D, Drago J, Borrelli E, Finkelstein DI, Horne MK (2002) Effects of long-term treatment with dopamine receptor agonists and antagonists on terminal arbor size. Eur J Neurosci 16:787-794.

Paxinos G, Franklin KBJ (2001) The mouse brain in stereotaxic coordinates, Ed 2. San Diego: Academic.

Penit-Soria J, Audinat E, Crepel F (1987) Excitation of rat prefrontal cortical neurons by dopamine: an in vitro electrophysiological study. Brain Res 425:263-274.

Peters Y, Barnhardt NE, O’Donnell P (2004) Prefrontal cortical up states are synchronized with ventral tegmental area activity. Synapse 52:143-152.

Pirot S, Godbout R, Mantz J, Tassin JP, Glowinski J, Thierry AM (1992) Inhibitory effects of ventral tegmental area stimulation on the activity of prefrontal cortical neurons: evidence for the involvement of both dopaminergic and GABAergic components. Neuroscience 49:857-865.

Robinson TE, Kolb B (1999a) Alterations in the morphology of dendrites and dendritic spines in the nucleus accumbens and prefrontal cortex following repeated treatment with amphetamine or cocaine. Eur J Neurosci 11:1598-1604.

Robinson TE, Kolb B (1999b) Morphine alters the structure of neurons in the nucleus accumbens and neocortex of rats. Synapse 33:160-162.

Robinson TE, Gorny G, Mitton E, Kolb B (2001) Cocaine self-administration alters the morphology of dendrites and dendritic spines in the nucleus accumbens and neocortex. Synapse 39:257-266.

Rosenberg DR, Lewis DA (1995) Postnatal maturation of the dopaminergic innervation of monkey prefrontal and motor cortices: a tyrosine hydroxylase immunohistochemical analysis. J Comp Neurol 358:383-400.

Seaman C, Anderson R, Emery B, Cooper HM (2001) Localization of the netrin guidance receptor, DCC, in the developing peripheral and enteric nervous systems. Mech Dev 103:173-175.

Seamans JK, Yang CR (2004) The principal features and mechanisms of dopamine modulation in the prefrontal cortex. Prog Neurobiol 74:1-58.

Sesack SR, Hawrylak VA, Melchitzky DS, Lewis DA (1998) Dopamine innervation of a subclass of local circuit neurons in monkey prefrontal cortex: ultrastructural analysis of tyrosine hydroxylase and parvalbumin immunoreactive structures. Cereb Cortex 8:614-622.

Shatzmiller RA, Goldman JS, Simard-Emond L, Rymar V, Manitt C, Sadikot AF, Kennedy TE (2008) Graded expression of netrin-1 by specific neuronal subtypes in the adult mammalian striatum. Neuroscience 157: 621-636.

Shewan D, Dwivedy A, Anderson R, Holt CE (2002) Age-related changes underlie switch in netrin-1 responsiveness as growth cones advance along visual pathway. Nat Neurosci 5:955-962.

Shi M, Guo C, Dai JX, Ding YQ (2008) DCC is required for the tangential migration of noradrenergic neurons in locus coeruleus of mouse brain. Mol Cell Neurosci 39:529-538.

Slopsema JS, van der Gugten J, de Bruin JP (1982) Regional concentrations of noradrenaline and dopamine in the frontal cortex of the rat: dopaminergic innervation of the prefrontal subareas and lateralization of prefrontal dopamine. Brain Res 250:197-200.

Smiley JF, Goldman-Rakic PS (1993) Heterogeneous targets of dopamine synapses in monkey prefrontal cortex demonstrated by serial section electron microscopy: a laminar analysis using the silver-enhanced diaminobenzidine sulfide (SEDS) immunolabeling technique. Cereb Cortex 3:223-238.

Spear LP (2000) The adolescent brain and age-related behavioral manifestations. Neurosci Biobehav Rev 24:417-463.

Srour M, Rivière JB, Pham JM, Dubé MP, Girard S, Morin S, Dion PA, Asselin G, Rochefort D, Hince P, Diab S, Sharafaddinzadeh N, Chouinard S, Théoret H, Charron F, Rouleau GA (2010) Mutations in DCC cause congenital mirror movements. Science 328:592.

Sternberger LA, Sternberger NH (1983) Monoclonal antibodies distinguish phosphorylated and nonphosphorylated forms of neurofilaments in situ. Proc Natl Acad Sci U S A 80:6126-6130.

Tan HY, Callicott JH, Weinberger DR (2007) Dysfunctional and compensatory prefrontal cortical systems, genes and the pathogenesis of schizophrenia. Cereb Cortex 17[Suppl 1]:i171-i181.

Tang F, Kalil K (2005) Netrin-1 induces axon branching in developing cortical neurons by frequency-dependent calcium signaling pathways. J Neurosci 25:6702-6715.

Tzschentke TM (2000) The medial prefrontal cortex as a part of the brain reward system. Amino Acids 19:211-219.

Van De Werd HJ, Rajkowska G, Evers P, Uylings HB (2010) Cytoarchitectonic and chemoarchitectonic characterization of the prefrontal cortical areas in the mouse. Brain Struct Funct 214:339-353.

Van Eden CG, Hoorneman EM, Buijs RM, Matthijssen MA, Geffard M, Uylings HB (1987) Immunocytochemical localization of dopamine in the prefrontal cortex of the rat at the light and electron microscopical level. Neuroscience 22:849-862.

Ventura R, Alcaro A, Cabib S, Conversi D, Mandolesi L, Puglisi-Allegra S (2004) Dopamine in the medial prefrontal cortex controls genotypedependent effects of amphetamine on mesoaccumbens dopamine release and locomotion. Neuropsychopharmacology 29:72-80.

Vezina P, Blanc G, Glowinski J, Tassin JP (1991) Opposed behavioural outputs of increased dopamine transmission in prefrontocortical and subcortical areas: a role for the cortical D-1 dopamine receptor. Eur J Neurosci 3:1001-1007.

Voorn P, Kalsbeek A, Jorritsma-Byham B, Groenewegen HJ (1988) The preand postnatal development of the dopaminergic cell groups in the ventral mesencephalon and the dopaminergic innervation of the striatum of the rat. Neuroscience 25:857-887.

Wang HD, Deutch AY (2008) Dopamine depletion of the prefrontal cortex induces dendritic spine loss: reversal by atypical antipsychotic drug treatment. Neuropsychopharmacology 33:1276-1286.

Wang HD, Stanwood GD, Grandy DK, Deutch AY (2009) Dystrophic dendrites in prefrontal cortical pyramidal cells of dopamine D1 and D2 but not D4 receptor knockout mice. Brain Res 1300:58-64.

West MJ, Slomianka L, Gundersen HJ (1991) Unbiased stereological estimation of the total number of neurons in the subdivisions of the rat hippocampus using the optical fractionator. Anat Rec 231:482-497.

Williams ME, Wu SC, McKenna WL, Hinck L (2003) Surface expression of the netrin receptor $\mathrm{UNC5} \mathrm{H} 1$ is regulated through a protein kinase C-interacting protein/protein kinase-dependent mechanism. J Neurosci 23:11279-11288.

Wolf ME, Kapatos G (1989) Flow cytometric analysis and isolation of permeabilized dopamine nerve terminals from rat striatum. J Neurosci 9:106-114

Wu KY, Zippin JH, Huron DR, Kamenetsky M, Hengst U, Buck J, Levin LR, Jaffrey SR (2006) Soluble adenylyl cyclase is required for netrin-1 signaling in nerve growth cones. Nat Neurosci 9:1257-1264.

Xu B, Goldman JS, Rymar VV, Forget C, Lo PS, Bull SJ, Vereker E, Barker PA, Trudeau LE, Sadikot AF, Kennedy TE (2010) Critical roles for the netrin receptor deleted in colorectal cancer in dopaminergic neuronal precursor migration, axon guidance, and axon arborization. Neuroscience 169: 932-949.

Yetnikoff L, Labelle-Dumais C, Flores C (2007) Regulation of netrin-1 receptors by amphetamine in the adult brain. Neuroscience 150:764-773.

Yetnikoff L, Arvanitogiannis A, Flores C (2010) The adult phenotype of netrin-1 receptor deficient mice is reversed by prepubertal administration of repeated amphetamine. Soc Neurosci Abstr 36:367.9.

Yetnikoff L, Almey A, Arvanitogiannis A, Flores C (2011) Abolition of the behavioral phenotype of adult netrin-1 receptor deficient mice by exposure to amphetamine during the juvenile period. Psychopharmacology. Advance online publication. Retrieved May 23, 2011. doi: 10.1007/ s00213-011-2312-6. 